\title{
Modification of titanium hydride for improved aluminium foam manufacture
}

\author{
B. Matijasevic-Lux ${ }^{a}$ J. Banhart ${ }^{\mathrm{a}, \mathrm{b}}$ S. Fiechter ${ }^{\mathrm{b}}$ O. Görke ${ }^{\mathrm{a}}$ \\ N. Wanderka ${ }^{b}$ \\ ${ }^{a}$ Institute of Materials Science and Technology, Technical University Berlin, \\ Hardenbergstr. 36, 10623 Berlin, Germany \\ ${ }^{\mathrm{b}}$ Hahn-Meitner-Institut Berlin, Glienicker Str. 100, 14109 Berlin, Germany
}

\begin{abstract}
Titanium hydride was used for foaming the aluminium casting alloy AlSi6Cu4. In order to improve foaming characteristics the $\mathrm{TiH}_{2}$ powder was subjected to various heat treatments prior to processing to shift hydrogen release up into the melting range of the alloy. Untreated and pre-treated powders were characterised by oxygen analysis, thermal analysis in connection with mass spectrometry applying various temperature profiles, X-ray diffraction and transmission electron microscopy. In addition, foaming trials were carried out based on various $\mathrm{TiH}_{2}$ powders. It was found that oxidation of $\mathrm{TiH}_{2}$ particles is responsible for the observed shift in decomposition temperature since heating under argon did not produce this effect. The shift can be tailored by choosing suitable pre-treatment parameters. For an appropriate choice a beneficial effect on foam morphology was found.
\end{abstract}

Acta Materialia 54(7), 1887-1900 (2006)

\section{Introduction}

Aluminium foams are porous metallic structures which combine typical properties of cellular materials with those of metals [1]. The high stiffness-to-mass ratio and good crash energy dissipation ability has led to a variety of applications especially in automotive industry [2,3].

The properties of metal foams depend on many morphological features such as pore size distribution, cell wall curvature, defects etc. [4]. Although the

$\overline{1}$ This work was supported by DFG, grant Ba 1170/4-2. 
exact interrelationship between properties and structure is not yet sufficiently known, one usually assumes that a uniform distribution of convex pores free of defects is highly desirable. The task for the experimentalist is to produce such structures. A short look at existing foams shows that there is still much potential for development since these often tend to be irregular [5].

Metals can be foamed in various ways [6]. One very promising method is the powder compact foaming process: a powder mixture of an alloy and a blowing agent is compacted to a dense precursor and then heated to above the melting point of the alloy [7]. Above the decomposition threshold of the blowing agent hydrogen is released which blows bubbles in the melting alloy. Titanium hydride was shown to be a suitable blowing agent for aluminium alloys [8] although other hydrides can also be used [9]. Hydrogen release from $\mathrm{TiH}_{2}$ starts around $400^{\circ} \mathrm{C}$, which is markedly below the melting point of most commercial aluminium alloys. This difference between decomposition and melting temperature causes the formation of irregular, crack-like pores in early expansion stages which then can lead to irregularities in the final product [10]. To minimize this temperature mismatch the melting point of the alloy can be lowered by further alloying - with possible unwanted side effects - or the decomposition threshold of the blowing agent can be raised by thermal pre-treatment. If $\mathrm{TiH}_{2}$ powder is pre-heated in air an oxide layer is formed on the surface of the particles. This layer delays gas release from the particles, so that ideally hydrogen is released during foaming only after the melting temperature of the alloy has been reached [11]. On the other hand, pre-treatments lead to hydrogen losses lowering foaming power. The task therefore is to find treatments which form a sufficiently thick oxide layer while a minimum of hydrogen is lost. Some pre-treatments have been suggested in metal foam literature [1117]. However, as the mechanisms leading to a retardation of gas evolution are not yet known, these parameters were found in a mostly empirical way.

We examine the kinetics of hydrogen release from untreated $\mathrm{TiH}_{2}$ as well as from $\mathrm{TiH}_{2}$ after pre-treatments in various atmospheres and study the influence of such pre-treatments on aluminium foam structure. For this purpose the decomposition of $\mathrm{TiH}_{2}$ powder is characterised by thermogravimetric analysis (TGA) combined with mass spectrometry (MS) and differential scanning calorimetry (DSC). Unlike most studies in the literature $[12-15,17]$ we rely on detecting hydrogen evolving from hydrides by a mass spectrometer. This allows us to separate gas release from other thermal effects caused by phase transformations and melting and provides an undisturbed measure for the effect which drives foaming. The method was shown to be useful in a previous study which, however, did not combine mass spectrometry and thermal analysis [9]. In order to separate effects of thermal decomposition and oxidation during pre-treatment we carry out pre-treatments under argon and air. Finally, we apply various heating profiles including constant heating rates and isothermal heating at two different temperatures to get closer to the situation 
during metal foam manufacture.

The hydride powders are also characterised by XRD, SEM and TEM. The latter allows for a direct visualisation of the oxidation effect. We consider both loose powders and $\mathrm{TiH}_{2}$ embedded in an aluminium matrix to obtain information about the effect of compaction on the properties of the oxide layer.

\section{Experimental procedures}

\subsection{Preparation of powders, foamable precursors and foams}

$\mathrm{TiH}_{2}$ powder supplied by Chemetall GmbH, Frankfurt (purity 98.9\%, nominally $\leq 63 \mu \mathrm{m}$ [18]) was used in this study. The powder was characterised in the state "untreated" and after several pre-treatments. Pre-treatments of the $\mathrm{TiH}_{2}$ powder were carried out isothermally at various temperatures $(440,460$, $\left.480,500,520^{\circ} \mathrm{C}\right)$ and times $(90,180$ and 360 minutes) both in an argon atmosphere (purified by a zirconium getter to $10^{-12} \mathrm{ppm}$ ) inside a tube furnace and under air in a chamber furnace. In the former case the powder was filled into flat ceramic crucibles (powder height $\approx 2 \mathrm{~mm}$ ) which were then placed into a horizontal quartz tube. After repeated evacuation and filling with argon a furnace was slid over the tube for the time required. In the latter case the ceramic crucibles were simply placed into a large volume chamber furnace and were left there for the time specified. Two further samples were obtained by using initially untreated samples which had then been subjected to an isothermal heat treatment for 180 minutes at $520^{\circ} \mathrm{C}$ inside the mass spectrometer both under air and argon flow to study the influence of continuous hydrogen removal during treatment. These samples are precisely the powders left after the experiments shown in Fig. 5.

After pre-treatment all powders were gently homogenised by tumbling in a container. The powders could be treated without individual particles sticking together (this became a serious problem at $\mathrm{T} \geq 540^{\circ} \mathrm{C}$ ). For obtaining bulk samples suitable for TEM the powders were cold pressed to small pellets of 6 $\mathrm{mm}$ diameter and $3 \mathrm{~mm}$ height prior to pre-treatment in order to avoid the necessity for deformation after heat treatment which is known to modify the decomposition characteristics [9].

Foamable precursors were prepared by mixing aluminium powder (Eckart, purity $99.74 \%,<160 \mu \mathrm{m}$ ), silicon powder (Ölschläger, purity $98.5 \%,<100 \mu \mathrm{m}$ ) and copper powder (Chempur, purity $99.8 \%,<250 \mu \mathrm{m}$ ) in fractions that led to an alloy composition AlSi6Cu4 and admixing $0.5 \mathrm{wt} . \% \mathrm{TiH}_{2}$ in either the 
untreated state or after one of the various pre-treatments. These powders were mixed for 90 minutes in a tumbling mixer to produce a homogeneous distribution of all components. The powder mixtures were then first pre-pressed at room temperature in a cylindrical die of $36 \mathrm{~mm}$ diameter, after which the die containing the powder mixtures was heated up to $450^{\circ} \mathrm{C}$ and held there for temperature equalisation. Subsequent hot pressing at about $200 \mathrm{MPa}$ for 30 min yielded tablets with more than $99 \%$ density. To monitor hydrogen release from the precursor small cubes $(l \approx 3 \mathrm{~mm}$ ) of precursor material, for the foaming experiments thin slices of $4 \mathrm{~mm}$ thickness were cut off the pressed tablets by electric discharge machining. For the TEM observations of $\mathrm{TiH}_{2}$ particles embedded in an aluminium matrix the same procedure as described above was applied with the only difference that no $\mathrm{Si}$ and $\mathrm{Cu}$ was added.

The foamable precursor was converted into foam by heating it to above its melting temperature. For this a sample was placed on a steel block pre-heated to the foaming temperature $650^{\circ} \mathrm{C}$ inside a furnace held at the same temperature. A thermocouple was in contact with the samples at all times so that we were able to monitor the temperature inside the foam during the entire process. Each foaming experiment was stopped as soon as a sample reached a given porosity and the foaming time $t_{f}$ and final foaming temperature $T_{f}$ was recorded. We tried to foam all samples to the same final volume corresponding to about $60 \%$ porosity. As we had no visual control of the foaming experiment we prepared several samples of each composition by varying foaming times slightly and selected the ones which had a porosity in the desired range for further examination. The preparation technique is explained in more detail in Refs. $[16,19,20]$.

\subsection{Powder analysis}

The oxygen content was determined by carrier gas hot extraction (CGHE) using the nitrogen/oxygen analyser Horiba EMGA 620 WC. The procedure of this method comprises the quantitative reduction of oxygen in the sample, the release of gaseous reaction products and their selective and quantitative detection. About $5 \mathrm{mg}$ of powder were first filled into a tin, then into a nickel capsule. This package was dropped into a graphite crucible which was then electrically heated up to about $2500^{\circ} \mathrm{C}$ for $40 \mathrm{~s}$. The capsules act as metal additives to obtain a homogenous reduction-assisting melt. At these high temperatures the oxygen in the sample reacts with carbon forming $\mathrm{CO}$ which was detected by infrared absorption analysis.

Particle size distributions of all powders were measured using a Sympatec Helos Vectra particle analyser. Powders were dispersed in water assisted by ultrasonic treatment to destroy agglomerates. In the applied laser diffraction 
spectrometry technique (LDS) the particle size distribution is derived from the patterns of a diffracted laser beam by using the Frauenhofer approximation as an optical model.

\subsection{Thermal analysis and mass spectrometry}

To study the decomposition of $\mathrm{TiH}_{2}$ as a function of temperature or time a Netzsch simultaneous thermal analyser STA 409C was used which allowed for simultaneous differential thermal analyis (DTA), thermo-gravimetric analysis (TGA) and mass spectrometry (MS) of both hydrogen and water. The analyser was equipped with a silicon carbide furnace connected to a quadrupole mass spectrometer via a skimmer coupling system. To obtain an optimum sensitivity the mass spectrometer was operated with a secondary electron multiplier. In all the measurements a constant amount of $150 \mathrm{mg}$ of either the untreated or pre-treated $\mathrm{TiH}_{2}$ powder or the foamable precursor were filled into the alumina crucible. After positioning of the crucible the thermobalance was evacuated three times and back-filled with argon prior to heating the sample under a continuous flow of argon (flow rate $150 \mathrm{~cm}^{3} / \mathrm{min}$ ).

\section{$2.4 \quad X$-ray diffraction}

A Bruker AXS diffractometer model D8 equipped with a graphite monochromator and a scintillation counter was used to determine the phases present in the $\mathrm{TiH}_{2}$ powders before and after pre-treatments in air at 480 and $520^{\circ} \mathrm{C}$. The diffraction patterns were measured for $2 \Theta$ ranging from $15^{\circ}$ to $90^{\circ}$ at steps of $0.02^{\circ}$. An acquisition time of $5 \mathrm{~s}$ per step using $\mathrm{CuK}_{\alpha}$ radiation was sufficient for successful phase analysis. The XRD patterns were evaluated using a JCPC standard diffraction database.

\subsection{Transmission electron microscopy}

$\mathrm{TiH}_{2}$ powders were characterized by TEM employing a Philips CM30 operated at $300 \mathrm{kV}$. Cold pressed pellets were cut into sizes suitable for TEM preparation and were then mechanically polished and subsequently ion-thinned. Cold pressing does not lead to a merger of individual particles so that these could be still separated in the TEM images. For studying $\mathrm{TiH}_{2}$ particles embedded in an aluminium matrix after compaction, i.e. in the foamable precursor, focused ion beam (FIB) milling was used to cut a thin foil out of a bulk sample including an interface between the $\mathrm{Al}$ matrix and a $\mathrm{TiH}_{2}$ particle. After this 
a micromanipulator was used to transfer the foil from the original sample to

a TEM grid coated with a porous carbon support film.

\section{Results}

After a characterisation of powder chemistry and powder size an extensive thermoanalytical programme was carried out. It is organized as outlined in Fig. 1. In Sec. 3.2 we characterise untreated $\mathrm{TiH}_{2}$ powder by thermal analysis in air and in an argon atmosphere to obtain a first overview of the concurring processes "hydrogen release" and "oxidation". Isochronal experiments at constant heating rate from $30-1200^{\circ} \mathrm{C}$ and isothermal experiments at $520^{\circ} \mathrm{C}-$ which is a typical pre-treatment temperature - are carried out. In a second step in Sec. 3.3 we characterise $\mathrm{TiH}_{2}$ powders pre-treated in air or argon prior to thermal analysis. Again constant heating rate traces and isothermal experiments - this time at $600^{\circ} \mathrm{C}$ which is a typical foaming temperature for aluminium alloys - are performed. Finally, hydrogen release from the foamable aluminium precursor is characterised under the same isothermal conditions.

The phases present in $\mathrm{TiH}_{2}$ before and after pre-treatment in air are determined by XRD. The oxide layers around individual $\mathrm{TiH}_{2}$ particles are investigated with TEM. Finally, it is shown that pre-treatment actually improves the structure of aluminium foams.

\subsection{Powder characterization}

In Fig. 2 the morphology of both untreated $\mathrm{TiH}_{2}$ powder and $\mathrm{TiH}_{2}$ pre-treated under air is made visible by SEM. The powders are angular shaped, the particle size is variable and the powder surface irregular. Obviously pre-treatment in air does not influence the morphology of the powders significantly.

The oxygen content of all the powders as determined by hot gas extraction is given in Fig. 3. Untreated $\mathrm{TiH}_{2}$ powder contains about 1 wt.\% oxygen. Treatment in air leads to a continuous increase up to $7 \mathrm{wt} . \%$ for a treatment at $520^{\circ} \mathrm{C}$ for 360 minutes. Treatment under argon leads to a slight decrease of the oxygen content down to 0.65 wt. $\%$. Changes in the colour of the $\mathrm{TiH}_{2}$ powder were observed during heat treatment in air. The initially dark grey powder turned blue at $480^{\circ} \mathrm{C}$, green at $500^{\circ} \mathrm{C}$ and light brownish to dark brown at $520^{\circ} \mathrm{C}$, depending on annealing time.

The powder size distribution of $\mathrm{TiH}_{2}$ obtained by laser particle analysis yielded: $\mathrm{d}_{10}=3.2 \mu \mathrm{m}, \mathrm{d}_{50}=14 \mu \mathrm{m}$ and $\mathrm{d}_{90}=31 \mu \mathrm{m}$. Analysis of the various metal pow- 
ders yielded the values: Al: $\mathrm{d}_{50}=67 \mu \mathrm{m}, \mathrm{Si}: \mathrm{d}_{50}=28 \mu \mathrm{m}, \mathrm{Cu}: \mathrm{d}_{50}=84 \mu \mathrm{m}$.

\subsection{Decomposition and oxidation behaviour of untreated $\mathrm{TiH}_{2}$ powder}

We frequently specify onset and peak temperatures of mass spectrometric or thermoanalytic data in this and the next section. The peak is defined as the location of the maximum value of the curve under consideration, while the onset is defined as the point where the curve has risen from the baseline to $1 \%$ of the peak value. Only in Fig. 7a we had to change this criterion to $2.5 \%$, while the sharp edge in Fig. $7 \mathrm{~b}$ allowed us to use this point to determine the onset point. These definitions are adapted to the quality of the data available. The onset temperatures obtained in this way are a bit arbitrary and do not reflect any physical transition in the material but they allow us to identify changes due to pre-treatments accurately.

Most measurements were repeated 2-3 times to be able to assess statistical errors. We found excellent reproducibility and therefore only show one curve. Only in Fig. 15 error bars are given to demonstrate accuracy of the measurements.

\subsubsection{Constant heating rate from 30 to $1200^{\circ} \mathrm{C}$}

Fig. 4a shows the release of hydrogen from untreated $\mathrm{TiH}_{2}$ powder as characterised simultaneously by various methods as a function of time and temperature. Argon flow and a heating rate of $10 \mathrm{~K} / \mathrm{min}$ were applied. The temperature course was linear throughout the entire range so that $\mathrm{T}(\mathrm{t})$ is not shown explicitly but can be read from the upper axis. As no oxygen is present the decrease in mass has to be ascribed to the release of hydrogen. The mass curve (TG) shows distinct changes in slope which become visible when showing the derivative (DTG). Two peaks and one shoulder can be observed in the DTG curve as well as in the mass spectroscopic (MS) curve. The first step of hydrogen release as identified by mass spectrometry applying the $1 \%$ criterion starts at $415^{\circ} \mathrm{C}$ (marked as "1"), the peak position is located at $524^{\circ} \mathrm{C}$. A second dehydrogenation step starts at about $560^{\circ} \mathrm{C}$ and reaches a maximum at $626^{\circ} \mathrm{C}$. The shoulder around $800^{\circ} \mathrm{C}$ indicates a third step which, however, is not further investigated since such high temperatures are never reached during foaming of aluminium alloys. Mass spectrometry of hydrogen (MS) and the derivative of the mass (-DTG) agree well even though they are slightly shifted against each other. DSC also yields a very similar result. Because of the higher sensitivity of the DSC measurement the starting point of decomposition becomes visible at a lower temperature around $390^{\circ} \mathrm{C} \mathrm{("2").} \mathrm{The} \mathrm{negative}$ maximum of the DSC curve indicates an endothermal reaction. Mass reduc- 
tion continuous up to temperatures around $920^{\circ} \mathrm{C}$ ("3"). The total mass loss up to this temperature is $3.78 \%$, which is close to the calculated value of $4 \%$ $\left(\mathrm{TiH}_{2} \rightarrow \mathrm{Ti}\right.$ corresponds to mass $\left.50 \rightarrow 48=-4 \%\right)$. The areas of the first and the other peaks are consistently related as 1:3.21, 1:3.22 and 1:3.01 for the MS, DTG and DSC curve, respectively. Hence, about $25 \%$ of the hydrogen gas is released in the first reaction. Some water is detected during heating of the powder over a wide temperature range, the water ion current being about 30 times smaller than that of hydrogen.

Fig. $4 \mathrm{~b}$ shows the behaviour of untreated $\mathrm{TiH}_{2}$ powder heated at a rate of $10 \mathrm{~K} / \mathrm{min}$ in air. Oxidation starts at $\approx 250^{\circ} \mathrm{C}$ ("1") and leads to a continuous mass increase. Due to strong exothermal effects the temperature curve departs from linearity at $600^{\circ} \mathrm{C}$ and leads to a peak at $680^{\circ} \mathrm{C}$ ("2") associated with a sudden increase of the slope of the TG curve. We observe both hydrogen and water evolution. Hydrogen is released above $380^{\circ} \mathrm{C}$ ("3"), while water evolution sets in at $510^{\circ} \mathrm{C}$ (" 4 "). The total mass gain from room temperature to $\mathrm{T}=1200^{\circ} \mathrm{C}$ is $59.7 \%$, which fits very well to the calculated increase of $60 \%$ $\left(\mathrm{TiH}_{2} \rightarrow \mathrm{TiO}_{2}\right.$ corresponds to mass $\left.50 \rightarrow 80=+60 \%\right)$.

\subsubsection{Isothermal pre-treatment of $\mathrm{TiH}_{2}$ powder}

Fig. 5a shows experiments on untreated $\mathrm{TiH}_{2}$ performed under argon applying a heating rate of $10 \mathrm{~K} / \mathrm{min}$ from room temperature up to $520^{\circ} \mathrm{C}$ followed by an isothermal treatment at this temperature for $180 \mathrm{~min}$. Different regimes of reaction can clearly be recognized in the MS, TG, -DTG and DTA curves. The first regime ("A") is the temperature range from 400 to $520^{\circ} \mathrm{C}$ (40 to $60 \mathrm{~min}$ ) and is associated with a loss of weight and strong evolution of hydrogen. A maximum of gas release is observed after 50 minutes at $500^{\circ} \mathrm{C}$ shortly before isothermal conditions have been reached. The negative maximum of the DTA curve indicates an endothermal reaction. The second regime ("B") of hydrogen release becomes dominant under isothermal conditions in the time range from 60-100 min and constant temperature. The MS, TG, DTG and DTA curves notably change their slopes and develop a shoulder. In the third regime ("C") the release of hydrogen levels off and tends to zero. Obviously, the TG, MS and DTA curves are coupled. The transition from the second to the third regime can be detected best from the changing slope of the MS curve. The shoulder of the MS curve matches with the shoulder of the DTA curve (see inset in Fig. $5 a)$.

In Fig. 5b the results of an analogous isothermal experiment under air are given. The increasing TG curve indicates significant oxidation above $250^{\circ} \mathrm{C}$ ("1") after a small initial mass change and reveals that the highest oxidation rate is found in the range between 460 and $520^{\circ} \mathrm{C}$. Hydrogen release as given by the MS curve gets notable at approximately $350^{\circ} \mathrm{C}$ ("2") and reaches a maximum 
at $507^{\circ} \mathrm{C}$ after $\approx 49$ min. This is slightly earlier than in Fig. 4 b reflecting inaccuracies in the starting conditions of each experiment. After some time at $520^{\circ} \mathrm{C}$ hydrogen evolution rapidly drops and reaches a low level after about 100 min ("3"). Associated with $\mathrm{H}_{2}$ evolution, we observe the formation of water from the corresponding mass spectrometric signal. If the isothermal holding temperature is $480^{\circ} \mathrm{C}$ instead of $520^{\circ} \mathrm{C}$ oxidation proceeds much slower which can be seen from the corresponding TG curve included in Fig. 5b.

\subsection{Decomposition of pre-treated powders}

The following experiments are based on powders pre-treated in air or argon prior to characterisation. At this stage no further oxidation occurs since thermal analysis is carried out under argon. $\mathrm{TiH}_{2}$ powder solely releases hydrogen which is also the case when metals are foamed.

\subsubsection{Constant heating rate from 30 to $1200^{\circ} \mathrm{C}$}

Fig. 6a shows the decomposition behaviour of $\mathrm{TiH}_{2}$ powders previously pretreated under argon. Starting from the curve for untreated powder which was already described in Fig. 4a, we see that heat treatment at $440^{\circ} \mathrm{C}$ for $180 \mathrm{~min}$ eliminates the first decomposition stage and leaves a single stage only. The single peak structure remains the same even for treatments at higher temperatures or for longer durations. The position of the remaining peak is slightly shifted to lower temperatures compared to that of the second peak of untreated $\mathrm{TiH}_{2}$. The maximum peak shift is $-12 \mathrm{~K}$. Another observation is that the onset of gas evolution at $415^{\circ} \mathrm{C}$ is not changed significantly by pre-treatments under argon, with all onset temperatures being between $413^{\circ} \mathrm{C}$ and $415^{\circ} \mathrm{C}$. Gas release levels off for temperatures beyond the peak and ends between $\approx 950^{\circ} \mathrm{C}$ for untreated powders or powders pre-treated at 440 and $460^{\circ} \mathrm{C}$, and $\approx 1100^{\circ} \mathrm{C}$ for powders pre-treated at 480 and $520^{\circ} \mathrm{C}$.

The decomposition curve for the powder pre-treated under the conditions described by Fig. 5a (curve marked with an asterisk in Fig. 6a) looks very different to the corresponding curve of the powder pre-treated in a closed argon-filled container for almost the same time and temperature. While onset and peak position are found at the same temperature, much less hydrogen is detected.

The powders pre-treated in air prior to thermal analysis show a different decomposition behaviour as demonstrated in Fig. 6b. As it was already observed for pre-treatment under argon, heat treatment for $180 \mathrm{~min}$ at $440^{\circ} \mathrm{C}$ in air eliminates the first decomposition stage. Unlike treatment under argon, however, treatment in air significantly changes the temperature of both the onset 
of gas evolution and the temperature at which maximum gas expansion occurs. Treatments up to $360 \mathrm{~min}$ or treatments at higher temperatures up to $520^{\circ} \mathrm{C}$ shift the onset by up to $+170 \mathrm{~K}$ and peak positions by up to $+52 \mathrm{~K}$. For all treatments gas release is smaller than that for untreated powders at $\mathrm{T} \geq 750^{\circ} \mathrm{C}$ and ceases earlier, namely at $\approx 900^{\circ} \mathrm{C}$ as compared to $\approx 950^{\circ} \mathrm{C}$ for untreated powder.

The decomposition curve for the powder exposed to the temperature course given in Fig. 5b prior to characterisation $\left(180\right.$ minutes at $520^{\circ} \mathrm{C}$ after a heating ramp, curve marked with an asterisk in Fig. 6b) shows the same onset and peak temperature but less hydrogen. Compared to the analogous effect under argon the reduction in hydrogen evolution is much smaller.

\subsubsection{Isothermal experiments at $600^{\circ} \mathrm{C}$ (after constant heating at $20 \mathrm{~K} / \mathrm{min}$ )}

Isothermal experiments at $600^{\circ} \mathrm{C}$ with a heating rate increased to $20 \mathrm{~K} / \mathrm{min}$ intended to simulate the temperature profile which occurs during foaming of common aluminium casting alloys. We first carried out experiments with $\mathrm{TiH}_{2}$ powder both in the untreated state and after heat treatments in air at various temperatures $\left(440,460,480,520^{\circ} \mathrm{C}\right.$ ) and times (90 min, $\left.180 \mathrm{~min}\right)$. Fig. 7 a shows a first release of hydrogen gas from the untreated powder at after 21 min at $420^{\circ} \mathrm{C}$ ("1") applying the $2.5 \%$ criterion (see Sec. 3.2 ). Gas release peaks after 34 minutes. At this time the maximum temperature has been reached. After the peak gas evolution drops. The curve resembles the one shown in Fig. $5 \mathrm{~b}$ although there the heating rate and isothermal temperature were lower. Employing oxidised powders, the onset of hydrogen evolution is shifted to between $510^{\circ} \mathrm{C}$ ("2") and $595^{\circ} \mathrm{C}$ ("3") depending on the pre-treatment in analogy to the constant heating rate experiments in Fig. 6b. The maximum of gas release is also shifted to later times for pre-treated powders.

\subsubsection{Decomposition of pre-treated powder in precursor}

The analogous isothermal experiments on foamable precursors employing the same parameters than for loose powders can be seen in Fig. 7b. Here the $\mathrm{TiH}_{2}$ particles are embedded in a dense aluminium alloy matrix. The ion current measured has a magnitude of about 1/20 the current in Fig. 7a reflecting the blowing agent content of $0.5 \mathrm{wt} . \%$ in the precursor. Hydrogen release from the untreated powder begins at $\approx 370^{\circ} \mathrm{C}(" 1 ")$ in this case. As the MS curve shows a pronounced edge we use this as point of hydrogen onset. For precursors made using pre-oxidised powders hydrogen release occurs between $\approx 450^{\circ} \mathrm{C}(" 2 ")$ and $\approx 570^{\circ} \mathrm{C}$ ("3") depending on pre-treatment parameters. Compared to the experiments on loose powders as shown in Fig. 7a hydrogen release from the precursor is shifted to an earlier moment for each 
of the pre-treatment states.

\section{$3.4 \quad X$-ray diffractometry}

XRD patterns for $\mathrm{TiH}_{2}$ powder pre-treated in air at $520^{\circ} \mathrm{C}$ for 90,180 and 360 min are shown in Fig. 8 and are compared with those for the untreated powder. The unmarked peaks correspond to $\mathrm{TiH}_{2}$ or sub-stoichiometric $\mathrm{TiH}_{x}$ compounds. The untreated powder was found to be single-phase. Its composition was identified as $\mathrm{TiH}_{1.924}$ (3.89 wt.\% hydrogen) with a fcc crystal structure $(\mathrm{a}=0.4448 \mathrm{~nm})$ using powder diffraction files. No signs of a tetragonal phase were found. After annealing in air the peaks corresponding to $\mathrm{TiH}_{x}$ are shifted to higher angles corresponding to a shift in lattice constant to $0.4392,0.4385$ and $0.4378 \mathrm{~nm}$ for 90,180 and $360 \mathrm{~min}$ at $520^{\circ} \mathrm{C}$, respectively. In addition, peaks corresponding to $\mathrm{Ti}_{3} \mathrm{O}$ and $\mathrm{TiO}_{2}$ (rutile) are detected, corresponding to a hexagonal and a tetragonal crystal structure, respectively.

\subsection{TEM investigations}

Fig. 9 (left) shows a bright field (BF) TEM micrograph of an untreated $\mathrm{TiH}_{2}$ particle. The surface of the particle does not show any signs of oxide layers in this image. In contrast, $\mathrm{TiH}_{2}$ particles pre-treated in air at $480^{\circ} \mathrm{C}$ for 180 min exhibit a clearly visible surface layer with a rather constant thickness of about $100 \mathrm{~nm}$ (Fig. 9, right). In the example given the $\mathrm{TiH}_{2}$ fragment was so thin that oxide layers can be identified on both sides. The oxide layers are polycrystalline as verified by the selected area electron diffraction pattern (SAED) which is given in Fig. 9 together with the pattern corresponding to the non-oxidised $\mathrm{TiH}_{2}$ core. From the position of the diffraction peaks a number of interplanar spacings $\mathrm{d}_{\exp }$ can be derived. These are given in the first column of Tab. 1.

We also carried out a qualitative analysis of the oxygen content inside the oxide layer. For this EDX measurements were performed along a line diagonally across the oxide layer. As a quantitative determination of light elements is difficult without precise standards only the relative change can be given. It was found that the oxygen content drops to about half the value at the outer side when crossing the layer.

In Fig. 10 a HRTEM image of this polycrystalline oxide layer around the core of a $\mathrm{TiH}_{2}$ particle is displayed. Small crystals between 3 and $10 \mathrm{~nm}$ in diameter oriented in various directions are observed.

Fig. 11 shows a BF TEM image of a pre-treated $\mathrm{TiH}_{2}$ particle embedded in 
compacted aluminium. The $\mathrm{TiH}_{2}$ particle and the $\mathrm{Al}$ matrix are marked in this figure. Magnified views of the oxide layer on both sides of the $\mathrm{TiH}_{2}$ particle are given. The layer shown on the left side splits up into two sub-layers. Thickness and structure of the layers appear uniform. The magnification on the right side shows further variations. Coming from right to left the double layer structure vanishes and turns into a thick zone containing oxide and aluminium. Possibly, the uniform structure of the oxide layer has been disrupted here by the mechanical forces occurring during compaction.

\subsection{Impact of pre-treatment on foaming behaviour}

Fig. 12 shows the interdependence between foaming time and the final temperature at which experiments were stopped in order to reach a desired expansion of about $60 \%$. The data were measured on samples containing differently pretreated $\mathrm{TiH}_{2}$. The heating conditions were identical in all cases. The final temperature $T_{f}$ increases steadily with foaming time $t_{f}$. This dependence reflects the temperature course in the sample during heating and is approximated by an exponential function in Fig. 12. The main observation is that a precursor which contains a blowing agent that has been more heavily pre-treated (at a higher temperature or for a longer time) needs longer (and correspondingly a higher final foaming temperature) to expand to a given volume.

The influence of the oxidation level of the blowing agent on the shape of the pores created during foaming is demonstrated in Fig. 13. Untreated $\mathrm{TiH}_{2}$ produced pores with jagged boundaries and a non-uniform size distribution. Associated with an increasing oxidation level of the hydride are notable changes in pore shape. Pores become more spherical and have smooth surfaces even for the shorter pre-treatments. Moreover, there is a positive influence on pore size distribution. Powders pre-treated at $520^{\circ} \mathrm{C}$ produce more uniform foams than powders pre-treated at lower temperatures. An extended pre-treatment for very long times leads to increasingly coarser foams.

\section{Discussion}

All three methods applied for the characterisation of powders, namely DSC (or DTA), TG and MS yield comparable results. The slight shift between the peak positions of DTG and MS is possibly caused by the time delay caused by the necessary transport of the released $\mathrm{H}_{2}$ from the furnace to the ionisation chamber of the quadrupole mass spectrometer. Obviously DSC is the most sensitive method since the onset of hydrogen release is observed at slightly lower temperatures as compared to TG and MS. 
Untreated $\mathrm{TiH}_{2}$ was found to have a fcc-based $\mathrm{CaF}_{2}$-structure which corresponds to the $\delta$-phase of the Ti-H system [21]. The tetragonal $\epsilon$-phase reported for temperatures below $\approx 25^{\circ} \mathrm{C}[22]$ is not observed, most likely because our laboratory temperature exceeded this value. Thermal characterisation of the untreated $\mathrm{TiH}_{2}$ yields results which are in a good agreement with measurements given in the literature, see e.g. Refs. [7,17]. Accordingly, hydrogen starts to be released from $\mathrm{TiH}_{2}$ at about $380-420^{\circ} \mathrm{C}$ with some variations between powders of different origin. Gergely found an onset at $465^{\circ} \mathrm{C}$, Kennedy and Lopez at $440^{\circ} \mathrm{C}$, but at higher heating rates [13,15] and possibly using a coarser powder and slightly different definitions of the onset temperature. Two decomposition peaks and one shoulder from untreated $\mathrm{TiH}_{2}$ powder are clearly visible in Fig. 4a, suggesting that the decomposition process occurs in three steps. $25 \%$ of the hydrogen is released in the first stage in accordance with the literature [15].

When heating of the sample is stopped at $520^{\circ} \mathrm{C}$ and isothermal conditions are applied (see Fig. 5a) gas evolution falls to well below the level seen when heating is continued. In the isothermal experiment a sharp peak is observed after 50 minutes shortly before the final temperature of $520^{\circ} \mathrm{C}$ has been reached. It corresponds to the first peak in Fig. 4a. After the peak a drop to much lower release rates is measured, whereas for continued heating only a small dip is observed before the second peak occurs. The shoulder in the isothermal peak between 60 and 100 minutes indicates that the temperature is high enough to ensure continued gas evolution. It is plausible to assume that the hydrogen remaining in the powder after passing the first decomposition stage is liberated in a second peak in Fig. 4a during continuous heating while it is slowly released at constant temperature over a longer period in the isothermal experiment in Fig. 5a. Accepting this, the shoulder in regime "B" in Fig. 5a would correspond mainly to the second decomposition stage. The total accumulated mass loss after $180 \mathrm{~min}$ at $520^{\circ} \mathrm{C}$ is around $2.5 \%$. Therefore, still $1.3 \%$ hydrogen is present in the hydride after that time. It is interesting to compare the MS curve in Fig. 5a with that in Fig. 7a corresponding to the untreated powder. Due to the higher heating rate in Fig. 7a the first and the second peak fall together. The shoulder present in Fig. 5a is missing and the entire hydrogen evolution has merged into one broad peak.

Fig. 3 reveals that the oxygen content drops during annealing under argon. This effect is not visible in the mass curve in Fig. 5a since the mass change due to hydrogen evolution dominates. We assume that oxygen present in the untreated powder reacts with some of the hydrogen and escapes from the powder as water vapour. Indeed we observe a very small water peak with the mass spectrometer (not shown).

The shapes of the TG curves in Fig. $4 \mathrm{~b}$ and Fig. $5 \mathrm{~b}$ reflect mass accumulation due to oxidation of the $\mathrm{TiH}_{2}$ powder. The exothermal reaction at $680^{\circ} \mathrm{C}$ ob- 
served in Fig. 4b coincides well with water formation indicating that it is caused by a reaction between hydrogen and oxygen. A similar effect was reported by Gergely [13] who observed a well-defined exothermal peak at $685^{\circ} \mathrm{C}$ in a DTA curve. Mass accumulation due to oxidation rapidly increases above about $500^{\circ} \mathrm{C}$. In the isothermal experiments at $480^{\circ} \mathrm{C}$ and $520^{\circ} \mathrm{C}$ the oxidation rate levels off as soon as temperature has reached a constant value after 50 minutes (Fig. 5b), whereas the mass gain continues up to complete oxidation if the temperature further increases. The reason for the levelling off is that at constant temperature the rate of reaction between oxygen and titanium is constant, but kinetics are determined by the time delay caused by the diffusion of oxygen through increasingly thick oxide layers. Assuming a simple model of spherical titanium particles which form a growing oxide shell of the same specific volume as the metal and composed of $\mathrm{TiO}_{2}$ only, the reaction rate is limited by the diffusion of oxygen through the already reacted layer. Diffusion through the layer with thickness $d=\left(R_{0}-R(t)\right)$ is governed by $d=\sqrt{6 D \Delta t}$, where $R_{0}$ is the original radius before oxidation, $D$ the diffusion constant of oxygen in $\mathrm{TiO}_{2}$ and $\Delta t$ the time needed to deliver the gas to the unreacted Ti core. Thus, the radius $R$ of the residual unreacted core can be represented by:

$$
\frac{d R}{d t}=-\frac{k}{\Delta t}=-k \frac{6 D}{\left(R_{0}-R\right)^{2}}
$$

where $k$ contains all the reaction coefficients. The solution of this differential equation is simply:

$$
R=R_{0}-(18 k D t)^{1 / 3}
$$

The mass increase is

$$
\Delta m=\frac{4 \pi}{3}\left(R_{0}^{3}-R^{3}\right)\left(\rho_{\mathrm{TiO}_{2}}-\rho_{\mathrm{Ti}}\right),
$$

where $\rho$ are the densities of the oxide and the metal. This function can be fitted to the measured mass increase by adjusting $k D$ (see Fig. $5 \mathrm{~b}$ ). With $k D$ found in this way, $R / R_{0}$ was 0.978 and 0.989 after 180 minutes at $520^{\circ} \mathrm{C}$ and $480^{\circ} \mathrm{C}$, implying that the oxide films on an average particle of $14 \mu \mathrm{m}$ diameter are $150 \mu \mathrm{m}$ and $75 \mu \mathrm{m}$ thick, respectively. These values agree qualitatively with the results of the TEM investigations (see Fig. 9). Obviously the agreement is not perfect but shows that the model of continuous oxidation is plausible. In reality the particles are angular which could enhance oxidation in early stages and the oxide layers have a larger volume than the unreacted metal which slows down diffusion in later stages. Fig. 5b also shows an isothermal oxidation experiment at $480^{\circ} \mathrm{C}$ (only TG). We see that the oxidation behaviour 
is very similar but the oxidation rate is smaller. The oxydation levels of $3.5 \%$ and $6 \%$ after $180 \mathrm{~min}$ at $480^{\circ} \mathrm{C}$ and $520^{\circ} \mathrm{C}$ given in Fig. 3, respectively, are in perfect agreement with those given in Fig. 5b. The oxydation levels measured by Gergely (Fig. 6.6 of [13]), however, are much lower. He observed a mass increase of just $1 \%$ after $150 \mathrm{~min}$ at $550^{\circ} \mathrm{C}$ and of $6 \%$ at $650^{\circ} \mathrm{C}$. This could be due to a coarser powder he might have used.

Oxidation also influences the shape of the decomposition peak observed in the isothermal experiments (Fig. 5). The peak gets much broader as an oxide layer builds up in Fig. 5b, whereas in the absence of oxidation the decomposition takes place in a much narrower temperature interval (see Fig. 5a). Integration of the MS curves in Fig. 5 yields $4.7 \times 10^{-6}$ As and $2.3 \times 10^{-6}$ As detected ions for samples pre-treated under argon and air, respectively. Therefore, oxidation effectively reduces dehydrogenation.

The changes of the decomposition characteristics of $\mathrm{TiH}_{2}$ powders by prior thermal and oxidising pre-treatments are the main concern of the current work. Fig. 6 explicitly proves the importance of oxidation since the annealing treatments were identical in the two cases with the exception of the type of ambient atmosphere. Whereas pre-treatments under air and Ar both remove the first decomposition peak, only annealing under air shifts both the onset of gas evolution and the maximum of gas evolution to higher temperatures. Thermal treatment without oxidation therefore merely reduces the amount of hydrogen and lowers the decomposition peak (see Fig. 6a). Oxidation as seen in Fig. 6b leads to the formation of oxide layers around the core of individual titanium hydride particles which then act as diffusion barriers delaying the evolution of hydrogen. Hydrogen not only has to diffuse through the bulk titanium matrix from the inner region of the particle towards the surface but also has to overcome the oxide barrier which is an additional kinetic hindrance. This effect is already known and has been exploited to control hydrogen evolution from $\mathrm{TiH}_{2}$ in metal foam manufacture [11,23]. Our results allow us to derive that the beneficial effect of pre-treatment is based on the formation of oxide layers and not on the removal of the first decomposition peak. Moreover, the results enable us to predict "good" pre-treatment parameters for making foams as we can try to match the decomposition characteristics with the melting properties of the respective alloy.

Han et al. find similar results for the peak of hydrogen evolution for pretreatments for 60 and 120 hours at $400^{\circ} \mathrm{C}$ [12] using a degassing apparatus. Lehmhus et al. use DSC to study the influence of various pre-treatments under air and argon [17]. They find the same basic phenomena, namely a shift of both onset and peak temperature for pre-treatments under air but the peak positions they determine are significantly lower than the ones shown in Fig. 6 . For powders pre-treated under argon they find a weak positive dependence of peak position on pre-treatment time which we do not observe. Kennedy carried 
out DSC studies on $\mathrm{TiH}_{2}$ powders pre-treated in air under non-isothermal conditions. Although his conditions are somewhat different the results are in accordance with our measurements. Gergely finds a similar behaviour for preoxidised $\mathrm{TiH}_{2}$, namely a shift of both onset and peak temperatures using DTA and TG [13].

The isothermal experiments at $600^{\circ} \mathrm{C}$ ("foaming simulations") shown in Fig. 7a confirm this picture. Both the onset and peak times are shifted to higher values by pre-treatment in air. Onset and peak positions found in both isochronal and isothermal experiments are displayed and compared in Fig. 14 (remember that the onset temperature (or time) was defined as the point at which 1 or $2.5 \%$ of the peak hight were exceeded, see Sec. 3.2). Analysis of the curves in Fig. 6 yields temperatures, that of Fig. 7 yields times. The lower part of Fig. 14 corresponds to the range of constant heating for both the isothermal and isochronal experiments (however at different heating rates), while in the middle part the temperature course for both experiments is different. For this reason isothermal and isochronal experiments can only be compared qualitatively. The onset of hydrogen evolution is shifted to higher temperatures (and longer times) with more intense pre-treatment reflecting the fact that oxidation is increasingly more effective at higher temperatures and longer times. The two curves for the isothermal and isochronal experiment are relatively similar despite the different heating rate showing that the onset of gas evolution is not very rate sensitive. The peak positions (middle curve) also move to higher temperatures but the dependence on pre-treatment temperature is less pronounced. As the variation of the onset temperature is larger, the difference between peak and onset temperature drops with increasing pre-treatment temperature (see data derived from Fig. 6b shown at top of Fig. 14). This is important as this means that the range of strong hydrogen evolution narrows from $211 \mathrm{~K}$ to $102 \mathrm{~K}$ when replacing untreated by pre-treated powder.

In a technological sense the result shown in Fig. $6 \mathrm{~b}$ is the most important one since it allows us to tailor the decomposition characteristics of the blowing agent. Higher annealing temperatures reduce the total amount of hydrogen available but shift the decomposition range to higher temperatures. As one would like to lose as little hydrogen as possible while shifting the temperatures to the highest values, a compromise has to be sought. Fig. 15 gives the total amount of hydrogen available after isothermal heating as determined by integration of the individual curves in Fig. 6a,b and Fig. 7a and normalising to the gas release from the untreated powder. Despite the scatter we can conclude that around $65-75 \%$ of the hydrogen are still available up to $480^{\circ} \mathrm{C}$ annealing temperature after which this fraction drops considerably (one point at 480-180 giving a very high value seems to be an artefact).

Fig. 15 reveals a notable discrepancy between Fig. 5a on the one hand and Figs. 6a and 7a on the other: Fig. 5a allows us to determine how much of 
the available hydrogen is driven out during pre-treatment at $520^{\circ} \mathrm{C}$ for 90 and 180 minutes, which is 60 and $68 \%$, respectively. The amount of hydrogen therefore remaining in the hydride, 40 and $32 \%$, has been added to Fig. 15 and should correspond to the integrals obtained from Fig. 6a. However, the resulting values are lower than expected, as indicated by arrow "A". Moreover, for the powders pre-treated in the thermobalance under a stream of Ar, only about $10 \%$ of the original amount of hydrogen is found (arrow "B"). The reason for the loss in hydrogen obviously is that during pre-treatment in the thermobalance while measuring Fig. 5 the stream of argon carries away the evolving hydrogen, thus facilitating decomposition. In contrast, in the experiments in Figs. 6a and 7a (except for the curves marked with an asterisk) pre-treatment was carried out in a closed tube furnace. A build-up of a hydrogen partial pressure can be expected here, thus retarding decomposition. A similar although much smaller effect is found for air. The air stream during pre-treatment in the thermobalance leads to a reduction of hydrogen content compared to pre-treatment in resting air (arrow "C"). In any case precise conditions for pre-treatment have to be defined in order to obtain meaningful results.

There is plenty of direct evidence for the existence of oxide layers. From Fig. 2 it becomes evident that oxidation of the powder does not change powder morphology. The only easily visible change is the colour of the powder. As thin films build up the optical properties change and the powder goes through a series of colours [16,24]. TEM observation clearly reveals these oxide films (Fig. 9). They are about $100 \mathrm{~nm}$ thick after a heat treatment at $480^{\circ} \mathrm{C}$ for 180 min and appear to be dense. Comparable thicknesses were also found by elipsometry [25] yielding values between 70 and $170 \mathrm{~nm}$ for the oxidation stages corresponding to ours (characterised by colours ranging from blue to green) [16]. Electron microdiffraction yields various values for interplanar spacings given in Tab. 1. These can be explained by assuming that the layer consists of two different oxides, namely $\mathrm{TiO}_{2}$ (rutile) and $\mathrm{Ti}_{3} \mathrm{O}$. This finding is in accordance with Ref. [15]. Qualitative EDX profiles confirm that the oxygen content drops to about half the value at the outer surface of the oxidised $\mathrm{TiH}_{2}$ particle when crossing the oxide layer. Thus it can be concluded that rutile forms an outer shell and $\mathrm{Ti}_{3} \mathrm{O}$ is located between the rutile layer and the $\mathrm{TiH}_{2}$ core. The XRD measurements confirm this picture (Fig. 8). The change of structure associated with hydrogen loss and the formation of the two types of oxides is observed, again in agreement with Ref. [15]. In the literature further transient oxides such as $\mathrm{TiO}, \mathrm{Ti}_{2} \mathrm{O}_{3}, \mathrm{Ti}_{3} \mathrm{O}_{5}$ [24], $\mathrm{Ti}_{2} \mathrm{O}, \mathrm{Ti}_{6} \mathrm{O}$ [26] and oxihydrides $\mathrm{TiO}_{x} \mathrm{H}_{y}$ [27] have been mentioned. None of these has be observed in our experiments.

$\mathrm{TiH}_{2}$ particles embedded in an aluminium powder compact also show an oxide layer which is well discernible from the aluminium matrix and the $\mathrm{TiH}_{2}$ core (see Fig. 11). In this case a division into two sub-layers is visible. The magnifi- 
cation on the left side shows that these layers are very uniform, appear dense and are about $100 \mathrm{~nm}$ thick. The magnified view on the right side shows that the oxide layers could be distorted in some areas. Coming from the lower right in this image one observes a double oxide layer structure which then ends in an area where the oxides could have piled up during the mechanical deformations associated with pressing. Such distorted areas could facilitate the escape of hydrogen from a $\mathrm{TiH}_{2}$ particle.

Gas release from the precursor as given in Fig. $7 \mathrm{~b}$ follows the same rules as from the loose powder. Pre-treatments lead to a delay of hydrogen evolution. Some of the hydrogen evolving during foaming is caught in the emerging pores but as samples are so small most of it reaches the surface of the sample and can eventually be detected by the mass spectrometer. In Fig. 14 the positions of the onset and maximum of hydrogen release from the $\mathrm{TiH}_{2}$ powder embedded in the precursor can be compared to the analogous data for the loose powder. Gas evolution from the precursor peaks earlier than for the loose powder although one might have expected the opposite arguing, e.g., that the entrapped hydrogen is held back by the metallic matrix or that decomposition of $\mathrm{TiH}_{2}$ is delayed by the hydrogen surrounding the blowing agent in the metal. The effect of earlier hydrogen release has already been observed previously $[9,17]$ and was explained by a possible partial fracture of the oxide layers on $\mathrm{TiH}_{2}$ particles during compaction [9]. The evidence given by one of the TEM images discussed above showing such a fracured oxide layer could support this hypothesis but a definite proof is still lacking. Fig. 15 shows that the amount of hydrogen available in the precursors roughly equals the amount in loose powders.

Foaming the selected aluminium alloy $\mathrm{AlSi} 6 \mathrm{Cu} 4$ with pre-treated powder delays foaming and increases temperatures at which a given state of foam evolution is reached by up to $45 \mathrm{~K}$ as seen in Fig. 12. This is exactly the effect sought, since gas evolution at higher temperatures is expected to be beneficial because the formation of cracks in the solid state is avoided and rounder pores are blown in the liquid or semi-solid state. The images shown in Fig. 13 confirm this picture. Foams blown with pre-treated $\mathrm{TiH}_{2}$ do have rounder and less jagged pores. Uniformity of cell size also seems to improve gradually with longer pre-treatment times but a quantitative measure for this effect is still lacking. The differences shown in Fig. 13 apply to a fairly early foaming stage, namely an expansion by a factor of less than 2.5. Fully expanded foams can have five times the original precursor volume. We also produced such foams and found that some differences are still visible but that these are more subtle than the differences in the early stage. Apparently there is some self-healing effect associated with the metal flow during foaming reducing some of the flaws. From a technological viewpoint, however, even small improvements of foam quality are important since they are expected to improve foam properties and process stability. 


\section{$5 \quad$ Summary and Conclusions}

- Titanium hydride releases hydrogen when heated to above about $390^{\circ} \mathrm{C}$.

- If heating is carried out under air an oxide layer grows with is roughly 100 nm thick after 180 minutes at $480^{\circ} \mathrm{C}$ and contains an outer shell of $\mathrm{TiO}_{2}$ and an inner shell of $\mathrm{Ti}_{3} \mathrm{O}$.

- A clear three-stage decomposition is only observed for untreated $\mathrm{TiH}_{2}$.

- Pre-treatments under argon reduce the amount of hydrogen stored in the hydride but do not change the onset and peak temperatures significantly.

- Pre-treatments under air reduce the amount of hydrogen and shift both onset and peak temperatures by $170 \mathrm{~K}$ and $52 \mathrm{~K}$, respectively. The temperature range of decomposition is compressed by pre-treatments.

- Gas flow during pre-treatment under argon and air as opposed to pretreatment under a resting atmosphere does not change the position of decomposition onset and the decomposition peaks but decreases the amount of hydrogen finally stored in the powders.

- Using pre-treated $\mathrm{TiH}_{2}$ for foaming AlSi6Cu4 alloys delays foaming and leads to a more uniform distribution of rounder pores. The best parameters found are close to 180 minutes at $480^{\circ} \mathrm{C}$ or $520^{\circ} \mathrm{C}$.

- Our results agree qualitatively with some data available in the literature. The differences observed suggest that the exact positions of onset and peak temperatures in thermal analysis do vary considerably with the source of the $\mathrm{TiH}_{2}$ powder.

- While it seems justified to claim that our results are of a general validity a fine-tuning of process parameters is recommended for anyone attempting to set up industrial production of $\mathrm{Al}$ foams.

\section{References}

[1] M.F. Ashby, A. Evans, N.A. Fleck, L.J. Gibson, J.W. Hutchinson, and H.N.G. Wadley. Metal foams - a design guide. Butterworth-Heinemann, London, 2000 .

[2] J. Banhart. Aluminium foams for lighter vehicles. International Journal of Vehicle Design, 37:114-125, 2005.

[3] H.-W. Seeliger. New aspects of getting aluminium-foam sandwich (AFS) parts into volume production. In J. Banhart, M.F. Ashby, and N.A. Fleck, editors, Cellular Metals and Metal Foaming Technology, pages 5-16. MIT-Verlag Berlin, Germany, 2001.

[4] T. Daxner, H.J. Böhm, M. Seitzberger, and F.G. Rammerstorfer. Modelling of cellular metals. In H.-P. Degischer and B. Kriszt, editors, Handbook of Cellular Metals, pages 245-280. Wiley-VCH, Weinheim, Germany, 2002. 
[5] H.P. Degischer and B. Kriszt. Handbook of Cellular Metals. Wiley-VCH, Weinheim, 2002.

[6] J. Banhart. Manufacture, characterisation and application of cellular metals and metallic foams. Progress in Materials Science, 46:559-632, 2001.

[7] F. Baumgärtner, I. Duarte, and J. Banhart. Industrialisation of P/M foaming process. Advanced Engineering Materials, 2:168-174, 2000.

[8] M. Weber. Herstellung von Metallschäumen und Beschreibung der Werkstoffeigenschaften. PhD thesis, Universität Clausthal, Clausthal-Zellerfeld, Germany, 1995.

[9] F. von Zeppelin, M. Hirscher, H. Stanzick, and J. Banhart. Desorption of hydrogen from blowing agents used for foaming metals. Composite Science and Technology, 63:2293-2300, 2003.

[10] L. Helfen, T. Baumbach, H. Stanzick, J. Banhart, A. Elmoutaoaukkil, and P. Cloetens. Viewing the early stage of metal foam formation by computed tomography using synchrotron radiation. Advanced Engineering Materials, 4:808-813, 2002.

[11] S.E. Speed. Foaming of metal by the catalysed and controlled decomposition of zirconium hydride and titanium hydride. US Patent 3,981,720, 1976.

[12] F. Han, Z. Zhu, J. Gao, and W. Song. Effect of oxidation treatment and surface filming on hydrogen degassing from $\mathrm{TiH}_{2}$. Metallurgical Transactions B, 29:1315-1319, 1998.

[13] V. Gergely. Metal route processing for production of metallic foams. $\mathrm{PhD}$ thesis, University of Cambridge, Cambridge, UK, 2000.

[14] A.R. Kennedy. The effect of $\mathrm{TiH}_{2}$ heat treatment on gas release and foaming in $\mathrm{Al}-\mathrm{TiH}_{2}$ preforms. Scripta Materialia, 47:763-767, 2002.

[15] A.R. Kennedy and V.H. Lopez. The decomposition behaviour of as-received and oxidised $\mathrm{TiH}_{2}$ foaming agent powder. Materials Science and Engineering, A357:258-263, 2003.

[16] B. Matijasevic, S. Fiechter, I. Zizak, O. Görke, N. Wanderka, P. SchubertBischoff, and J. Banhart. Decomposition behaviour of as-received and oxidised $\mathrm{TiH}_{2}$ powder. In H. Danninger and R. Ratzi, editors, Proceedings PM2004 Powder Metallurgy World Congress Vienna, volume 4, pages 149-155. European Powder Metallurgy Association, Shrewsbury, UK, 2004.

[17] D. Lehmhus and G. Rausch. Tailoring titanium hydride decomposition kinetics by annealing in various atmospheres. Advanced Engineering Materials, 6:313$330,2004$.

[18] R. Kresse. Characteristics and handling of titanium hydride. In J. Banhart, M.F. Ashby, and N.A. Fleck, editors, Metal Foams and Porous Metal Structures, pages 109-110. MIT-Verlag Berlin, Germany, 1999. 
[19] A. Bütow. Strukturuntersuchungen an Metallschäumen in verschiedenen Entwicklungsstadien. Master's thesis, TU Berlin, 2004.

[20] J. Banhart, D. Bellmann, and H. Clemens. Investigation of metal foam formation by microscopy and ultra small-angle neutron scattering. Acta Materialia, 49:3409-3420, 2001.

[21] A. San Martin and F.D. Manchester. The H-Ti (hydrogen-titanium) system. Bulletin of Alloy Phase Diagrams, 8:30-42, 1987.

[22] R.L. Crane, S.C. Chattoray, and M.B. Strope. A room-temperature polymorphic transition of titanium hydride. Journal of Less-common Metals, 25:225-227, 1971.

[23] V. Gergely and T.W. Clyne. The FORMGRIP process: foaming of reinforced metals by gas release in precursors. Advanced Engineering Materials, 2:168-174, 2000 .

[24] V.A. Lavrenko, V.Z. Shemet, L.A. Petrov, O.A. Teplov, and S.K. Dolukhanyan. High temperature oxidation of titanium hydride powders. Oxidation of Metals, 33:177-189, 1990.

[25] T. Fukuzuka, K. Shimogori, H. Satoh, and F. Kamikubo. On the beneficial effect of the titanium oxide film formed by thermal oxidation. In H. Kimura and O. Izumi, editors, Titanium 80, pages 2783-2792. AIMM and Petroleum Engineers, 1980.

[26] V.N. Fokin, Y.I. Malov, E.E. Fokina, S.L. Troitskaya, and S.P. Shilkin. Investigation of interactions in the $\mathrm{TiH}_{2}-\mathrm{O}_{2}$ system. International Journal of Hydrogen Energy, 20:387-389, 1995.

[27] A.R. Gromov, N.N. Kouznetsova, S.L. Yudina, and V.V. Lunin. The investigation of titanium hydride oxidation process. Journal of Alloys and Compounds, 261:269-272, 1997. 


\section{Tables}

Table 1

Interplanar spacings $\mathrm{d}_{\text {exp }}$ in the oxide layer around $\mathrm{TiH}_{2}$ particles annealed at $480^{\circ} \mathrm{C}$ for $180 \mathrm{~min}$ as measured by SAED. The 2 nd and 4 th column contain values calculated from lattice parameters for $\mathrm{TiO}_{2}$ and $\mathrm{Ti}_{3} \mathrm{O}$ taken from the literature [22] assuming one of the crystallographic directions given in columns 3 and 5 .

\begin{tabular}{|c|c|c|c|c|}
\hline $\begin{array}{c}\text { experimental d } \\
\text { from SAED }\end{array}$ & \multicolumn{4}{|c|}{ calculated d } \\
$\mathrm{d}_{\text {exp }}(\AA)$ & $\mathrm{d}(\AA)$ & {$[\mathrm{h}, \mathrm{k}, \mathrm{l}]$} & $\mathrm{d}(\AA)$ & {$[\mathrm{h}, \mathrm{k}, \mathrm{l}]$} \\
\hline 4.6 & - & - & 4.7 & {$[003]$} \\
3.2 & 3.2 & {$[110]$} & 3.2 & {$[103]$} \\
2.8 & - & - & 2.8 & {$[005]$} \\
2.3 & 2.29 & {$[200]$} & 2.3 & {$[006]$} \\
2.2 & 2.18 & {$[111]$} & 2.2 & {$[113]$} \\
2.1 & 2.05 & {$[210]$} & 2.1 & {$[202]$} \\
1.9 & - & - & 1.9 & {$[115]$} \\
1.6 & 1.6 & {$[211]$} & 1.6 & {$[210]$} \\
\hline
\end{tabular}




\section{Figures}

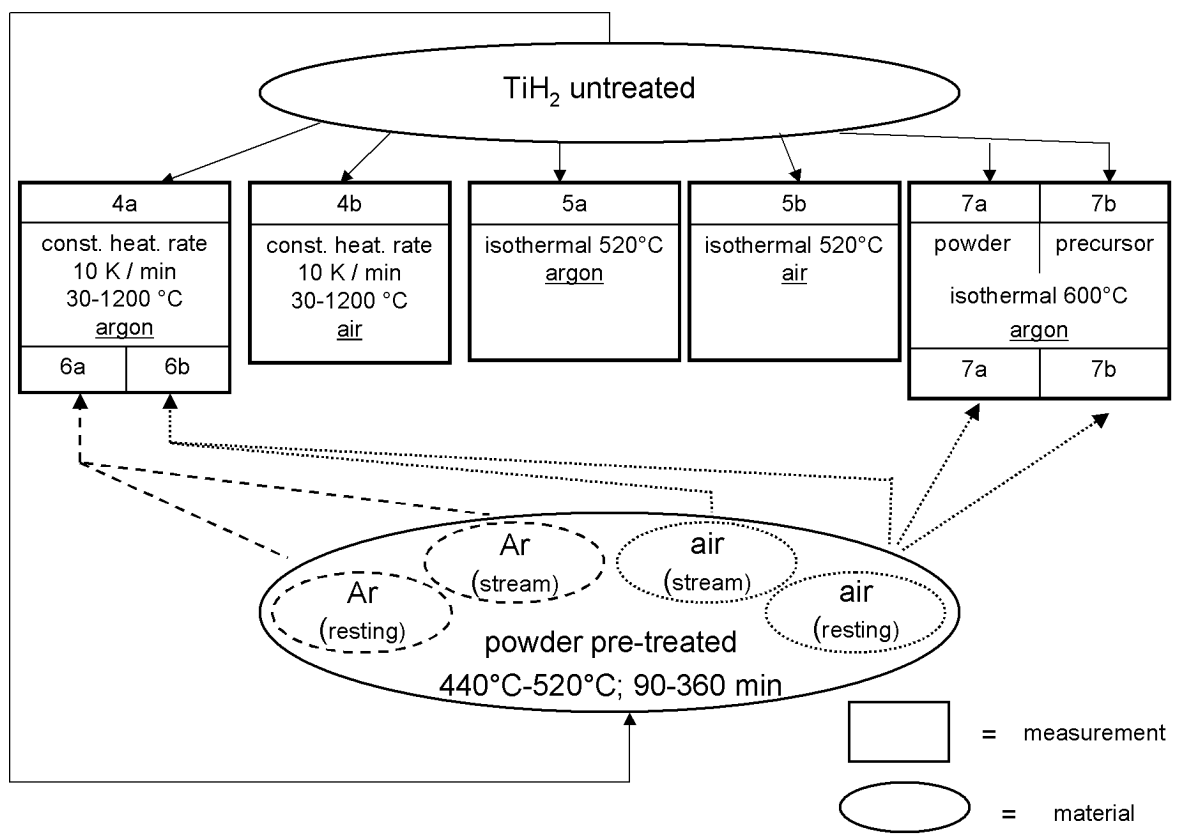

Fig. 1. Overview of all the thermo-analytical experiments performed. 


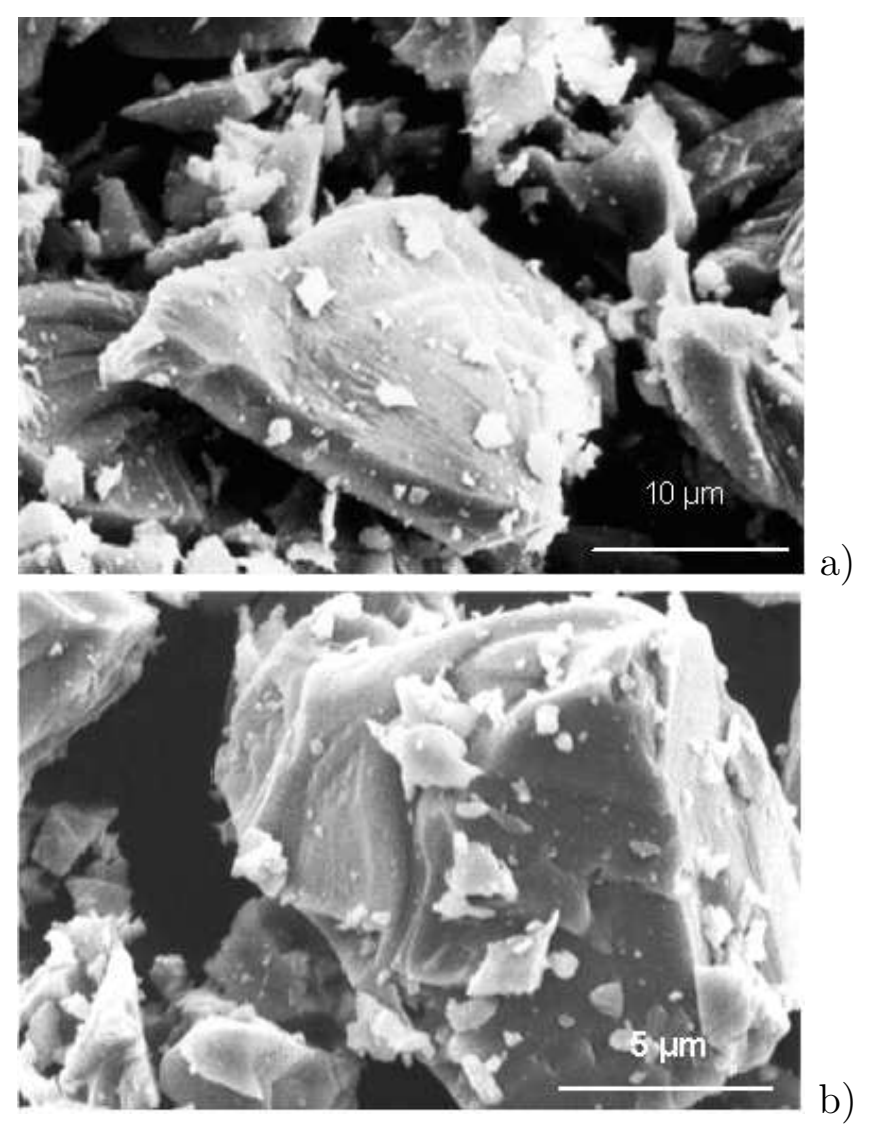

Fig. 2. SEM images of $\mathrm{TiH}_{2}$ powder particles; a) untreated, b) pre-treated in air at $480^{\circ} \mathrm{C}$ for 180 minutes. 


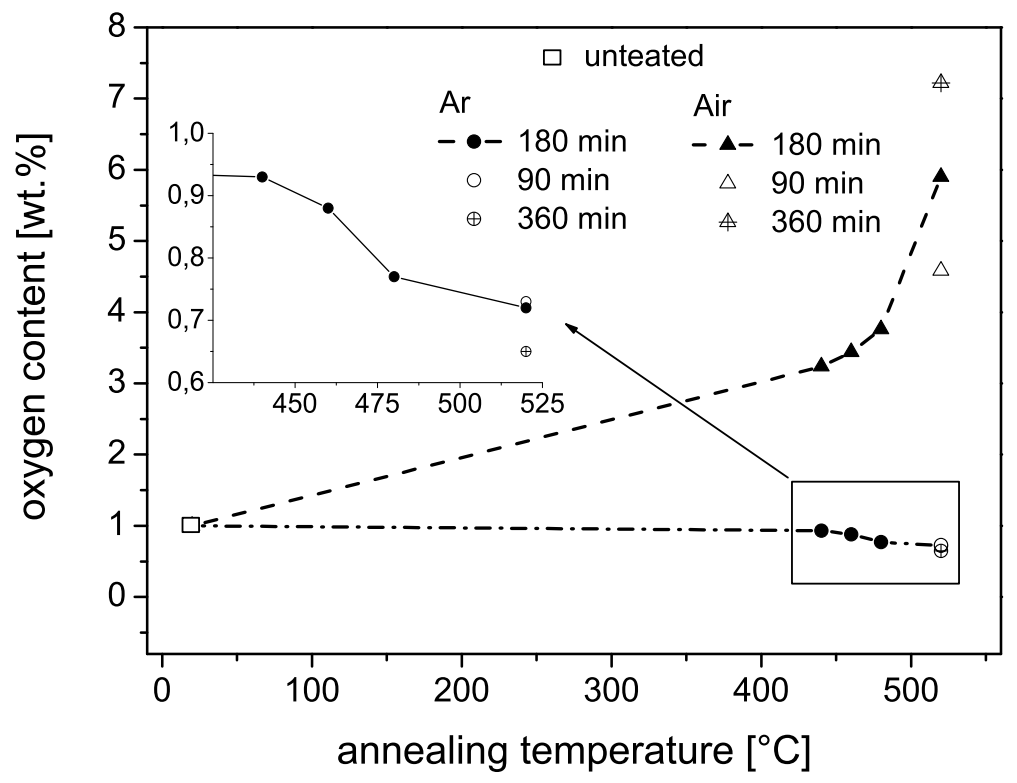

Fig. 3. Oxygen content of $\mathrm{TiH}_{2}$ powder after treatment at various temperatures and times under air and argon. 


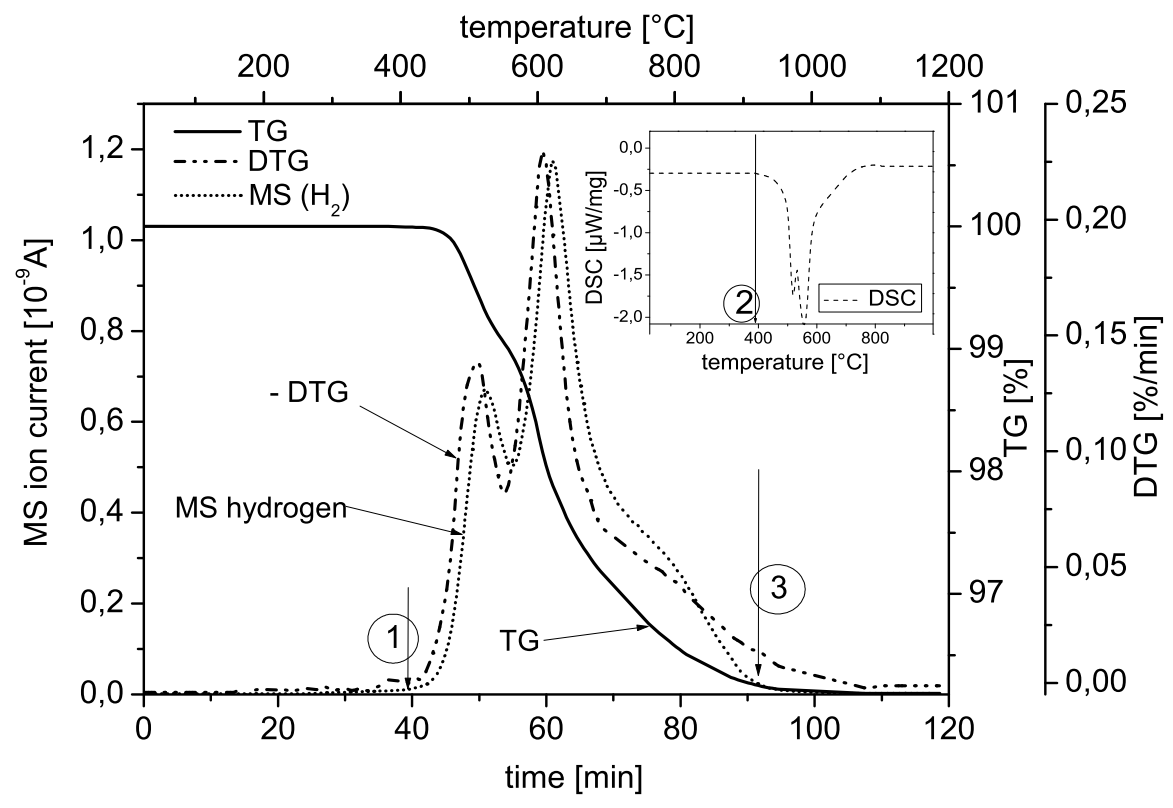

a)

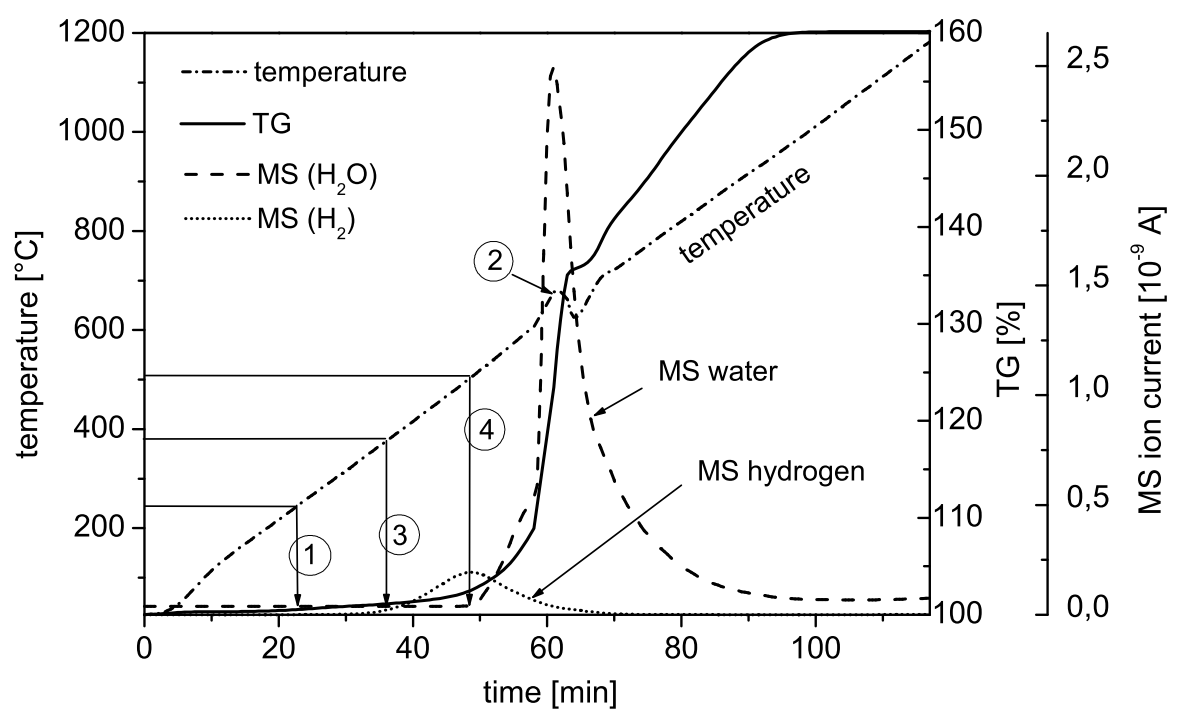

b)

Fig. 4. Analysis of untreated $\mathrm{TiH}_{2}$ powder heated from $30^{\circ} \mathrm{C}$ to $1200^{\circ} \mathrm{C}$ at $10 \mathrm{~K} / \mathrm{min}$. Calorimetric (DSC), mass (TG), mass change (-DTG $=-\mathrm{d} / \mathrm{dt}(\mathrm{TG}))$ and mass spectrometric (MS) signals for $\mathrm{H}_{2}$ and $\mathrm{H}_{2} \mathrm{O}$ (b) are shown. The numbers in circles mark specific temperatures discussed in the paper; a) experiment under Ar, b) in air. 


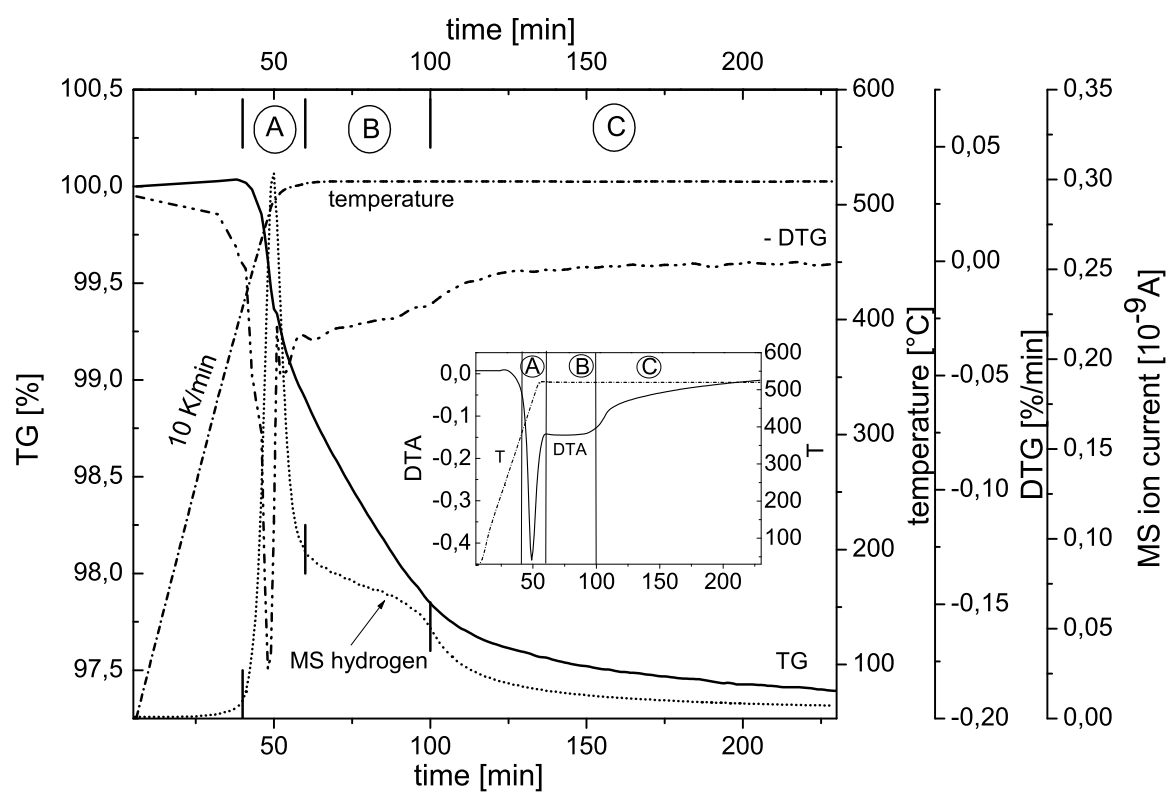

a)

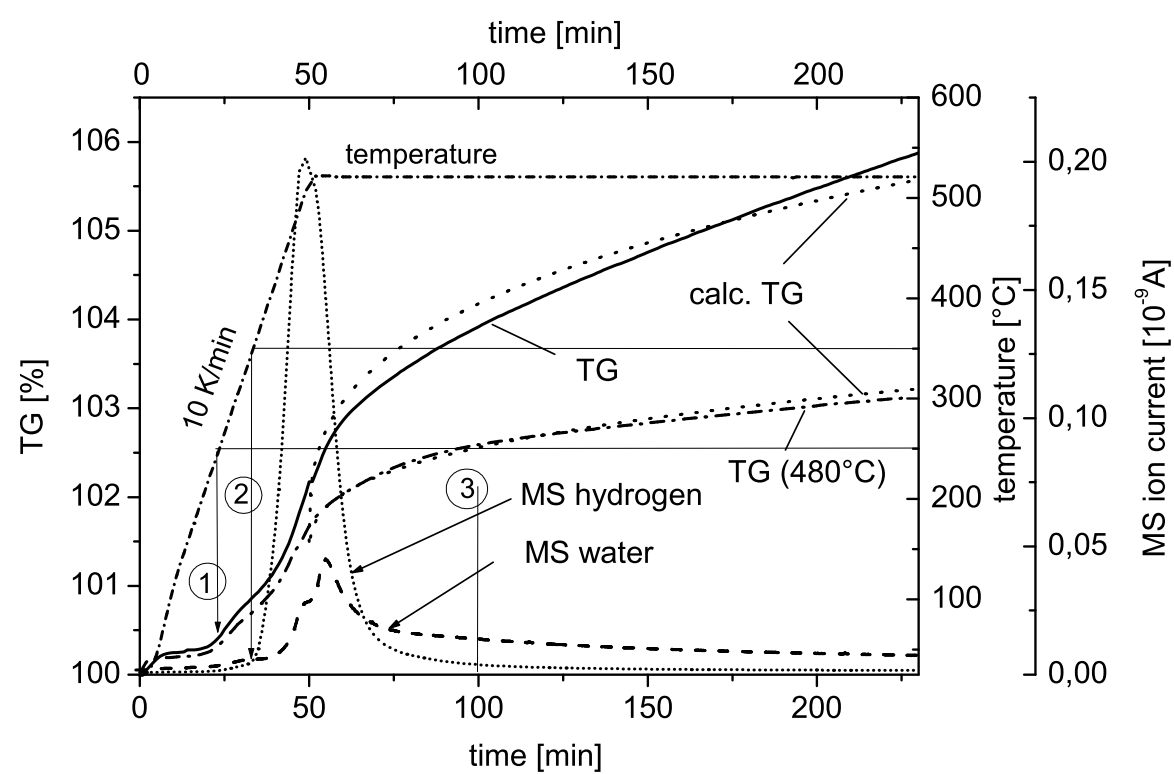

b)

Fig. 5. Analysis of untreated $\mathrm{TiH}_{2}$ powder heated up to $520^{\circ} \mathrm{C}$ and held there. Calorimetric (DTA), mass (TG), mass change (DTG) and mass spectrometric signals (MS) for hydrogen and water (b) are given. Letters (numbers) in circles denote reaction ranges (temperatures) as discussed in the paper; a) experiment under Ar flow, b) under air. The dash-dotted line is a TG curve obtained at $480^{\circ} \mathrm{C}$, dotted lines are fit curves calculated using Eqs. 2 and 3. 


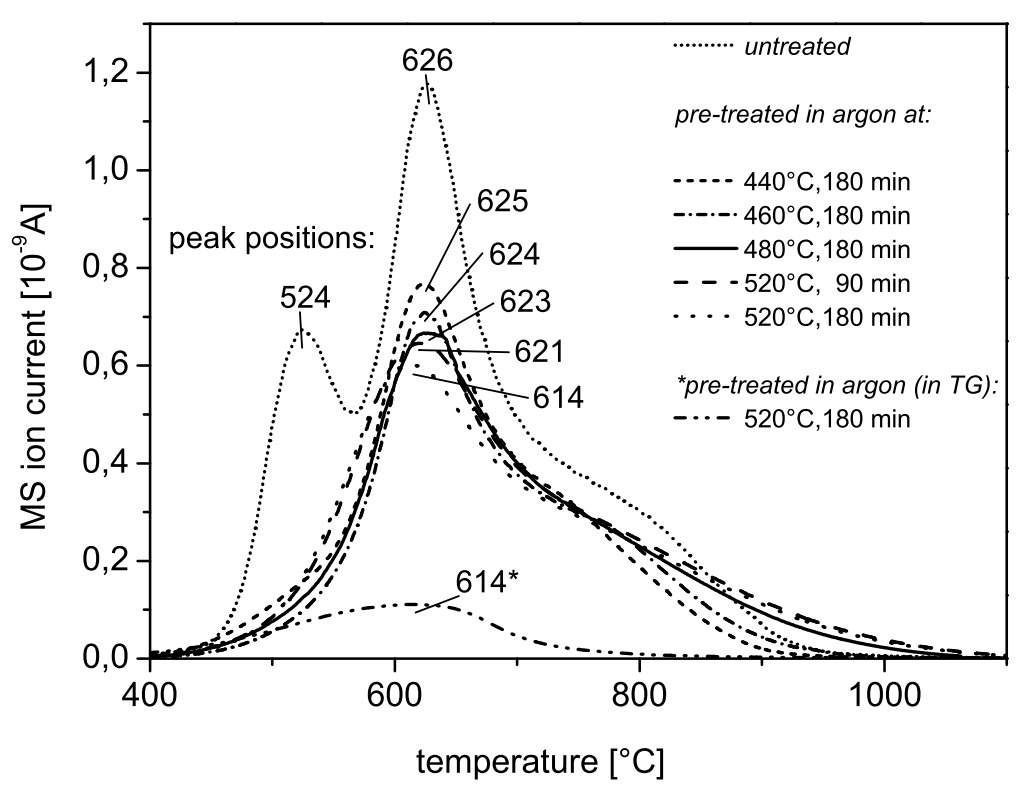

a)

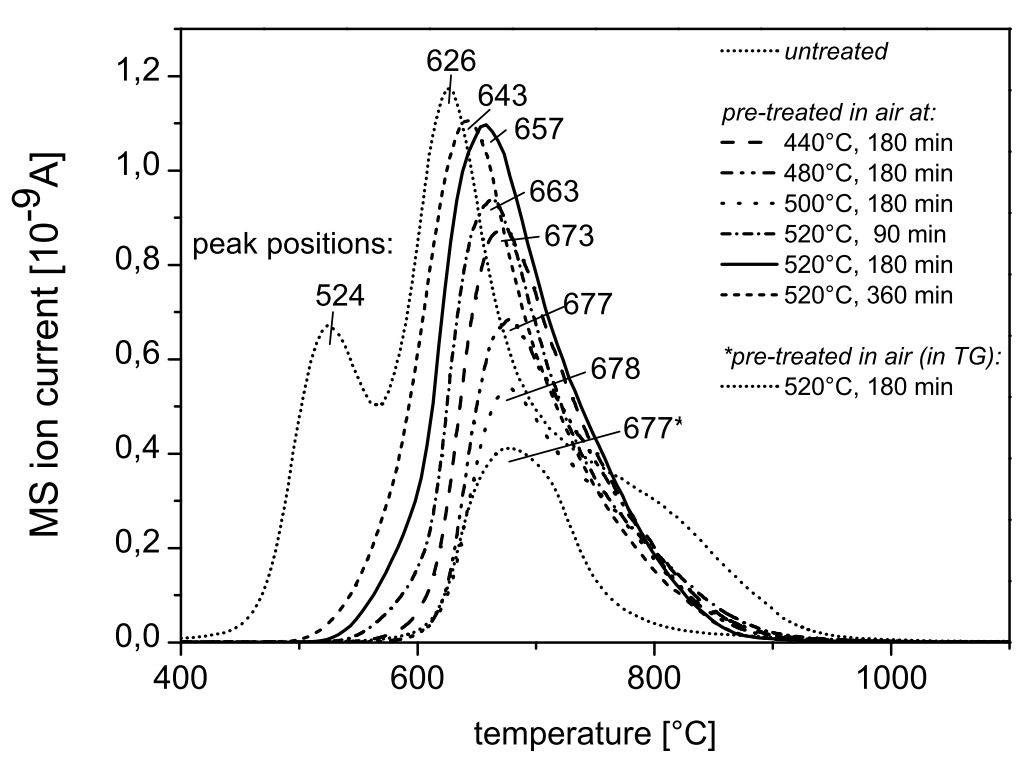

b)

Fig. 6. Mass spectrometric analysis of pre-treated $\mathrm{TiH}_{2}$ powders during heating from $30^{\circ} \mathrm{C}$ to $1200^{\circ} \mathrm{C}$ at $10 \mathrm{~K} / \mathrm{min}$ in an argon atmosphere (low temperature range omitted). Curves markes with an asterisk were obtained on samples pre-treated during the isothermal TG measurements shown in Fig. 5. Curve for untreated powder as already given in Fig. 4a is shown for comparison. Peak positions are specified in the diagrammes (in ${ }^{\circ} \mathrm{C}$ ); a) powders pre-treated under $\mathrm{Ar}, \mathrm{b}$ ) pre-treatment in air. 


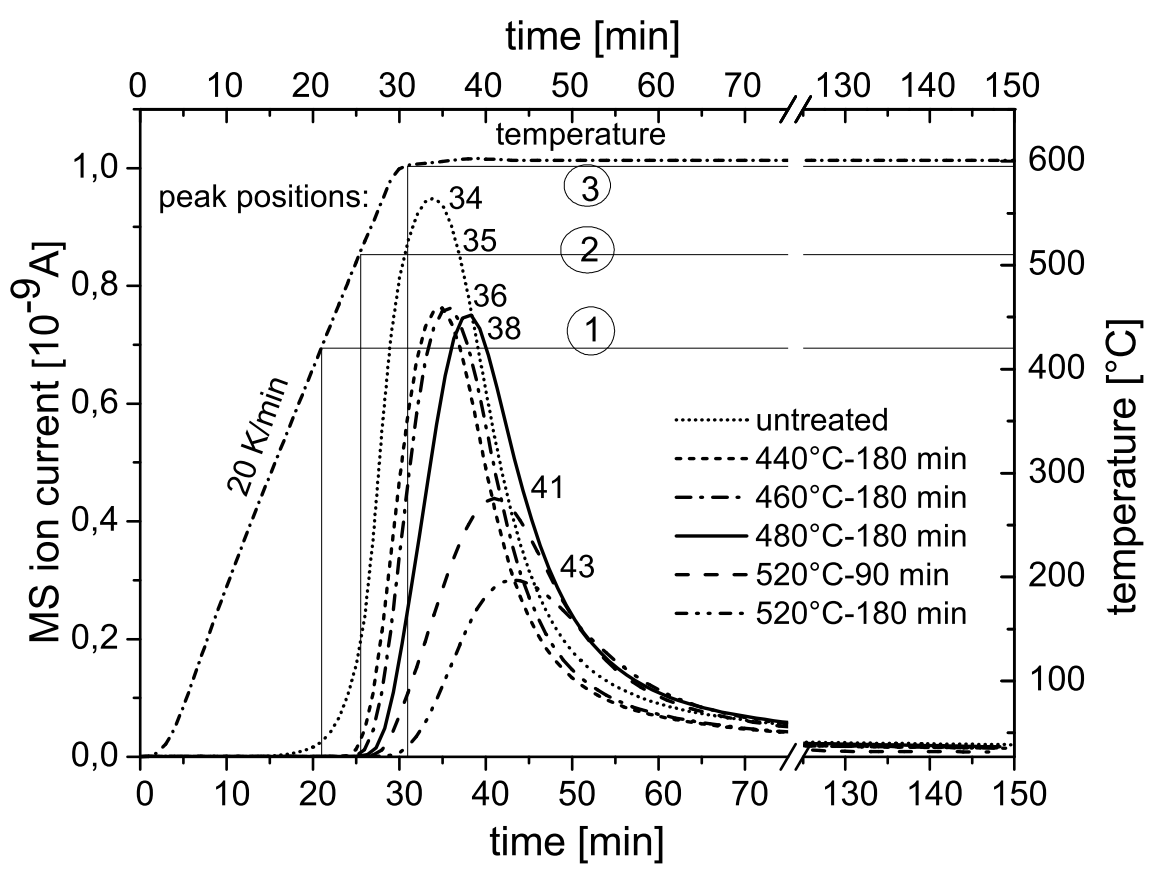

a)

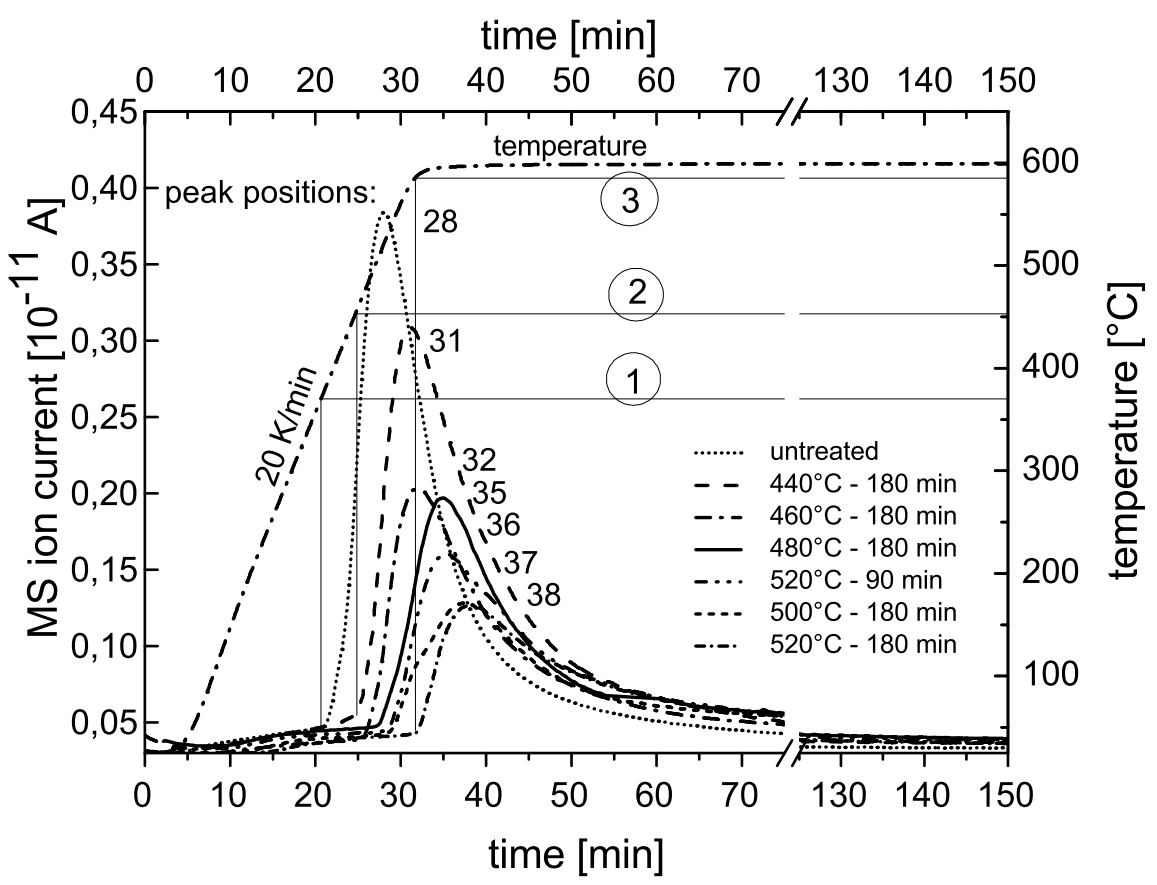

b)

Fig. 7. Mass spectrometric analysis of $\mathrm{TiH}_{2}$ powders pre-treated under air (analysis is carried out under Ar). Isothermal conditions at $600^{\circ} \mathrm{C}$ apply after heating at $20 \mathrm{~K} / \mathrm{min}$. Numbers denote times at which $\mathrm{H}_{2}$ evolution peaks (minutes); a) loose $\mathrm{TiH}_{2}$ powder, b) $\mathrm{TiH}_{2}$ in foamable precursor. 


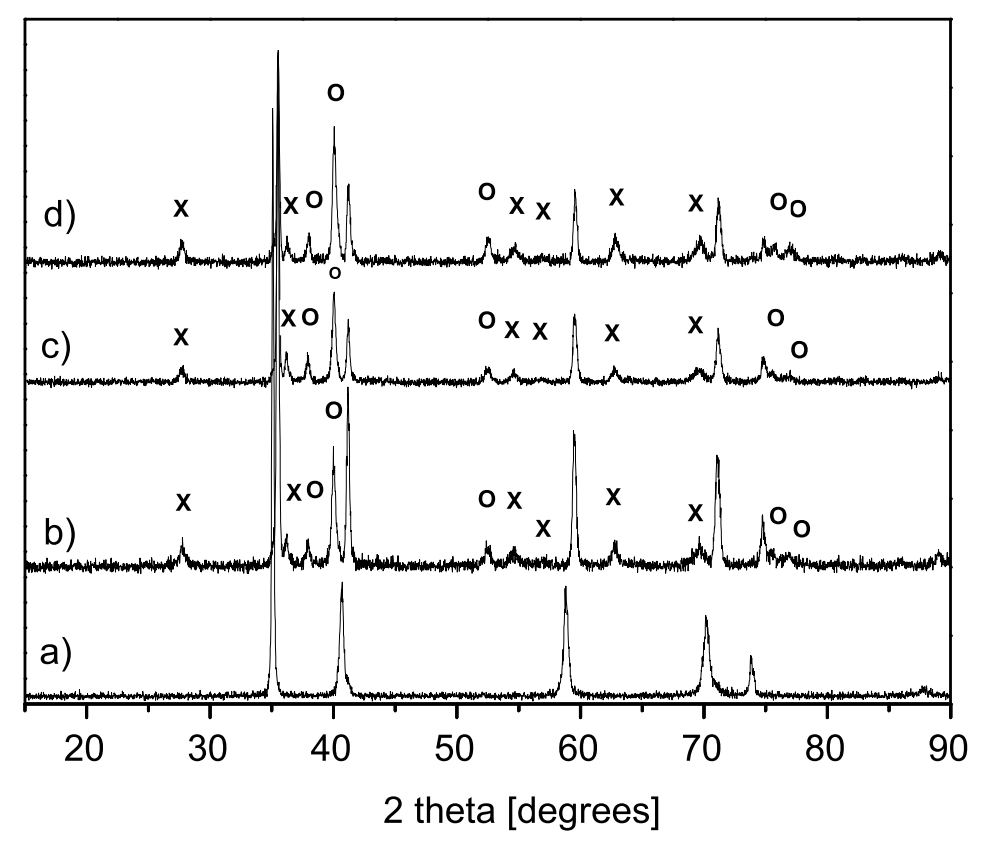

Fig. 8. XRD patterns for $\mathrm{TiH}_{2}$ powder; a) untreated, b-d) pre-treated in air at $520^{\circ} \mathrm{C}$ for 90,180 and $360 \mathrm{~min}$; $\mathrm{x}: \mathrm{TiO}_{2}, \mathrm{o}: \mathrm{Ti}_{3} 0$.
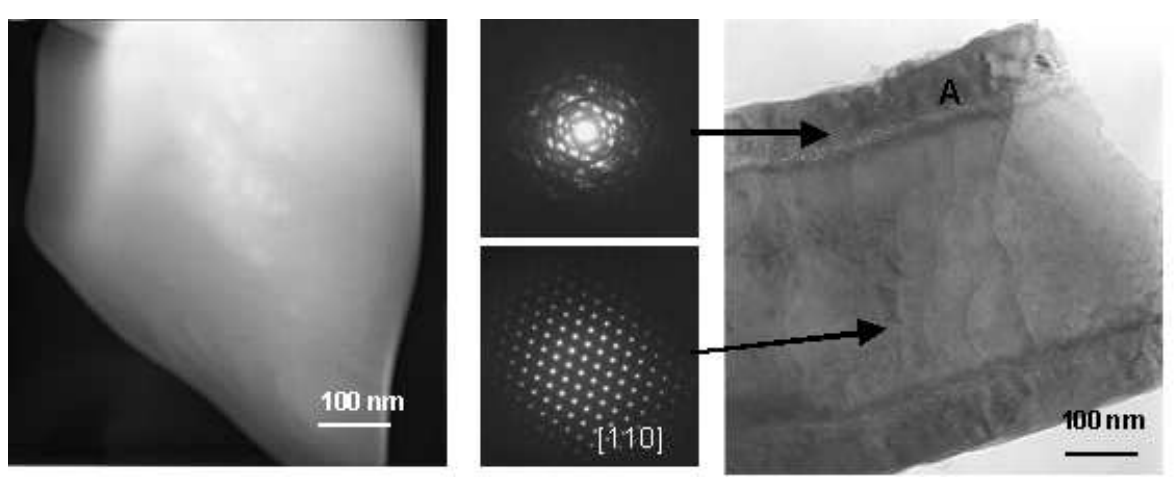

Fig. 9. Bright field TEM images of, left: untreated $\mathrm{TiH}_{2}$ particle, right: particle pre-treated in air at $480^{\circ} \mathrm{C}$ for $180 \mathrm{~min}$. The corresponding electron diffraction patterns within the [110]-zone axis of the $\mathrm{TiH}_{2}$ particle as well as the oxide layer around the core (marked "A") are shown in the middle. 


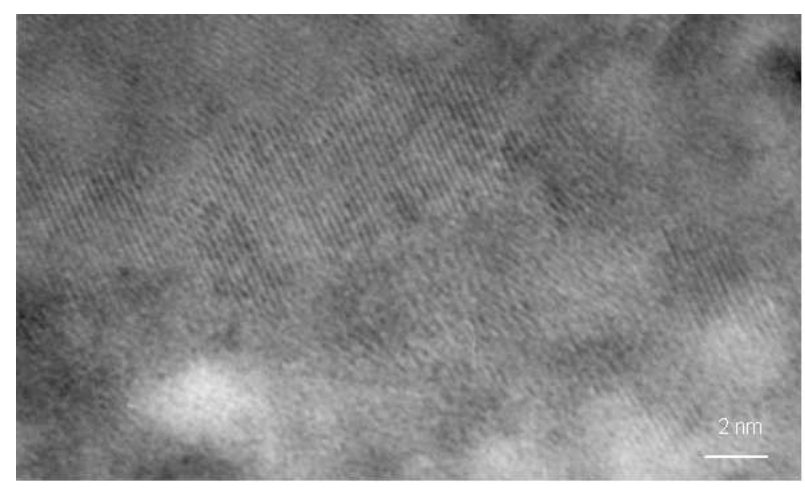

Fig. 10. HRTEM image of polycrystalline oxide layer around the core of $\mathrm{TiH}_{2}$ particle pre-treated in air at $480^{\circ} \mathrm{C}$ for $180 \mathrm{~min}$.

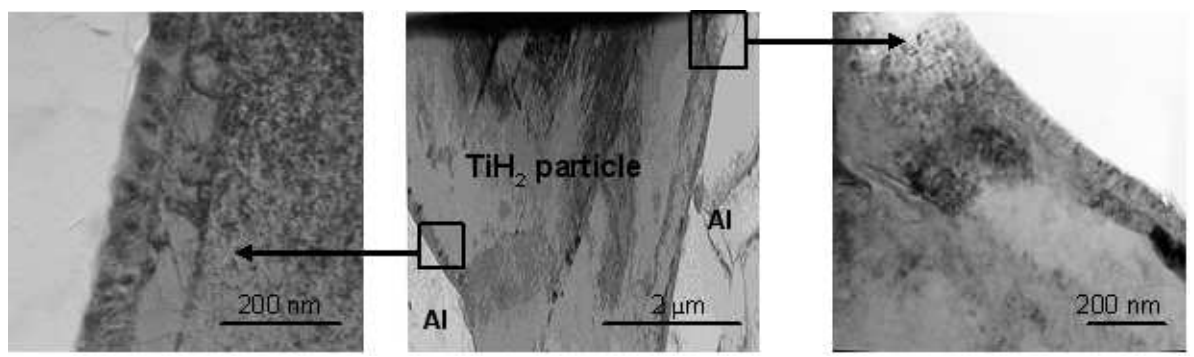

Fig. 11. Bright field TEM image of $\mathrm{TiH}_{2}$ particle pre-treated in air at $480^{\circ} \mathrm{C}$ for 180 min and embedded in an $\mathrm{Al}$ matrix by powder pressing. Enlarged views of image in the centre are shown on the left and right. 


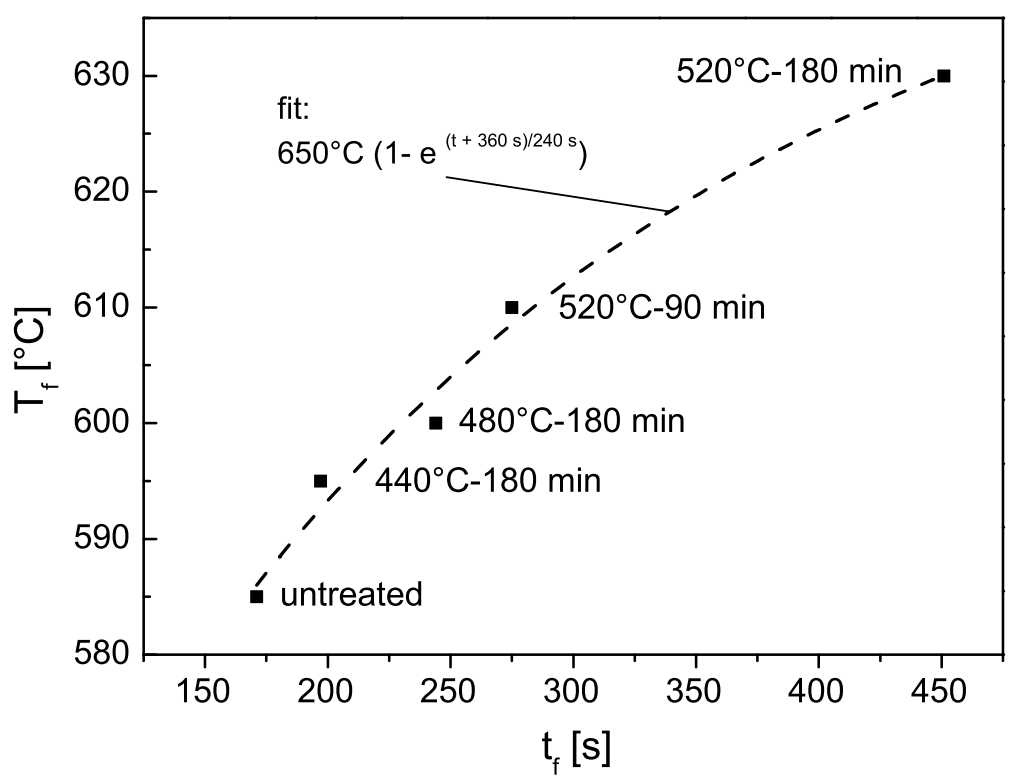

Fig. 12. Final sample temperature $\mathrm{T}_{f}$ vs. foaming time $\mathrm{t}_{f}$ for aluminium samples foamed up to a given porosity level of $\approx 60 \%$ with $\mathrm{TiH}_{2}$ pre-treated in different ways as specified. Furnace temperature was $650^{\circ} \mathrm{C}$. 

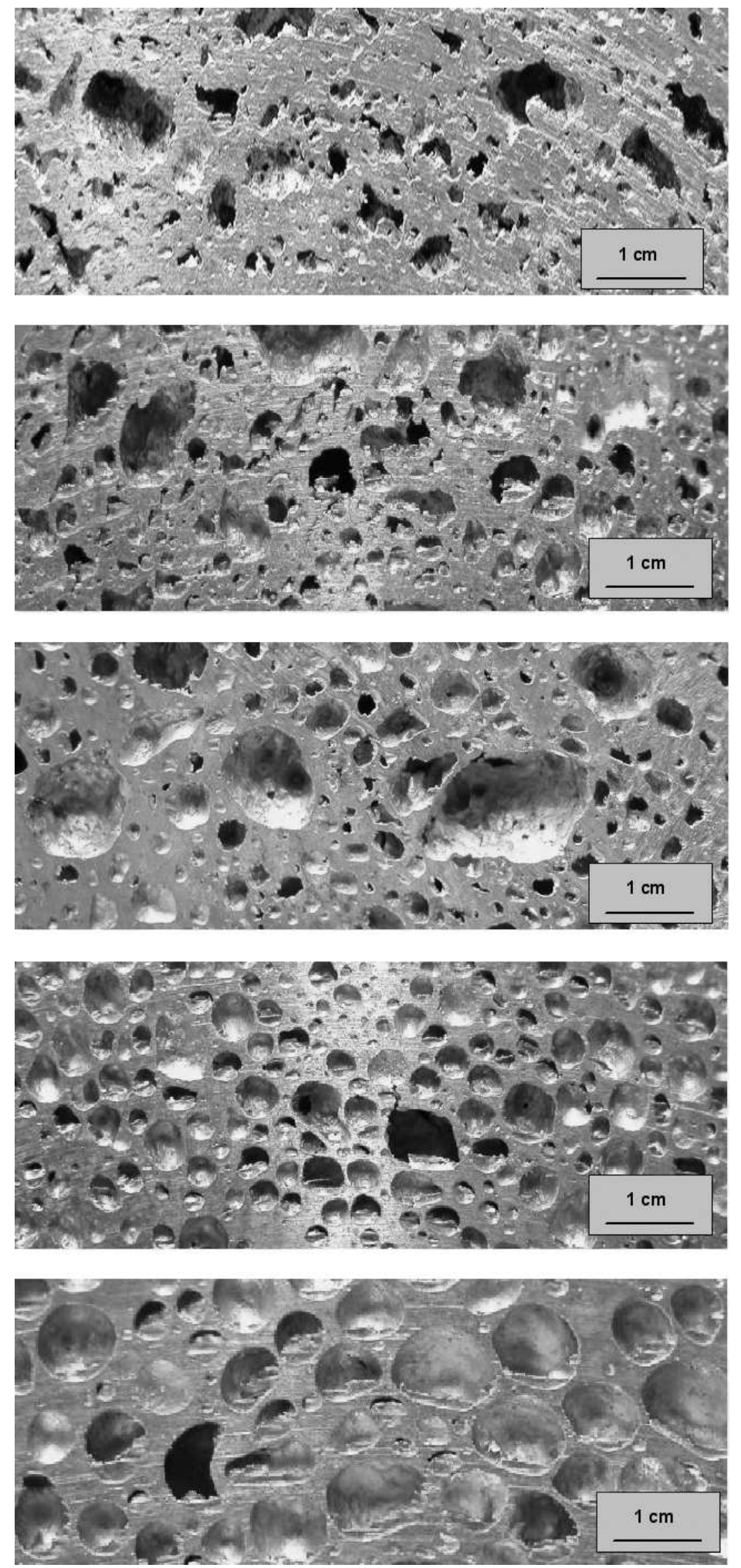

Fig. 13. AlSi6Cu4 foamed using a) untreated $\mathrm{TiH}_{2}$ (porosity $\mathrm{P}=53 \%$ ), b) pre-treated $\mathrm{TiH}_{2}, 440^{\circ} \mathrm{C}, 180 \min (\mathrm{P}=56 \%)$, c) $480^{\circ} \mathrm{C}, 180 \min (\mathrm{P}=61 \%)$, d) $520^{\circ} \mathrm{C}, 90 \mathrm{~min}$ $(\mathrm{P}=60 \%)$, e) $520^{\circ} \mathrm{C}, 180 \mathrm{~min}(\mathrm{P}=57 \%)$. The direction of expansion was from bottom to top. 


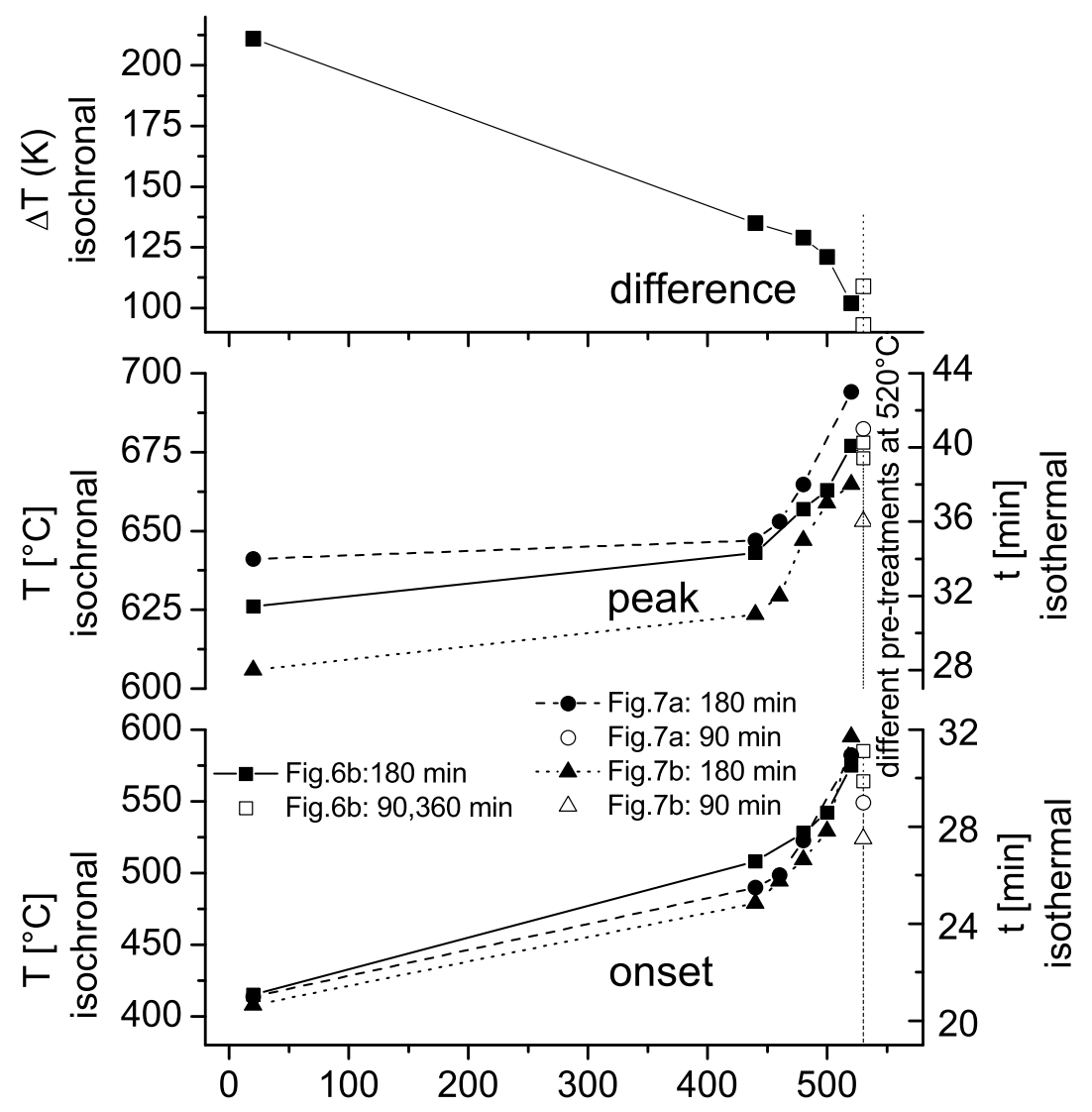

Fig. 14. Position of onset (lower) and peak (middle) of gas evolution derived from the results shown in Fig. 6b and Fig. 7a/b. Temperatures are given in the former, times in the latter case. Open symbols correspond to $520^{\circ} \mathrm{C}$ but have been moved slightly to the right for better visibility. Upper: difference between onset and peak temperature $\Delta T=T_{\text {peak }}-T_{\text {onset }}$ is shown for the isochronal measurement of Fig. $6 \mathrm{~b}$. 


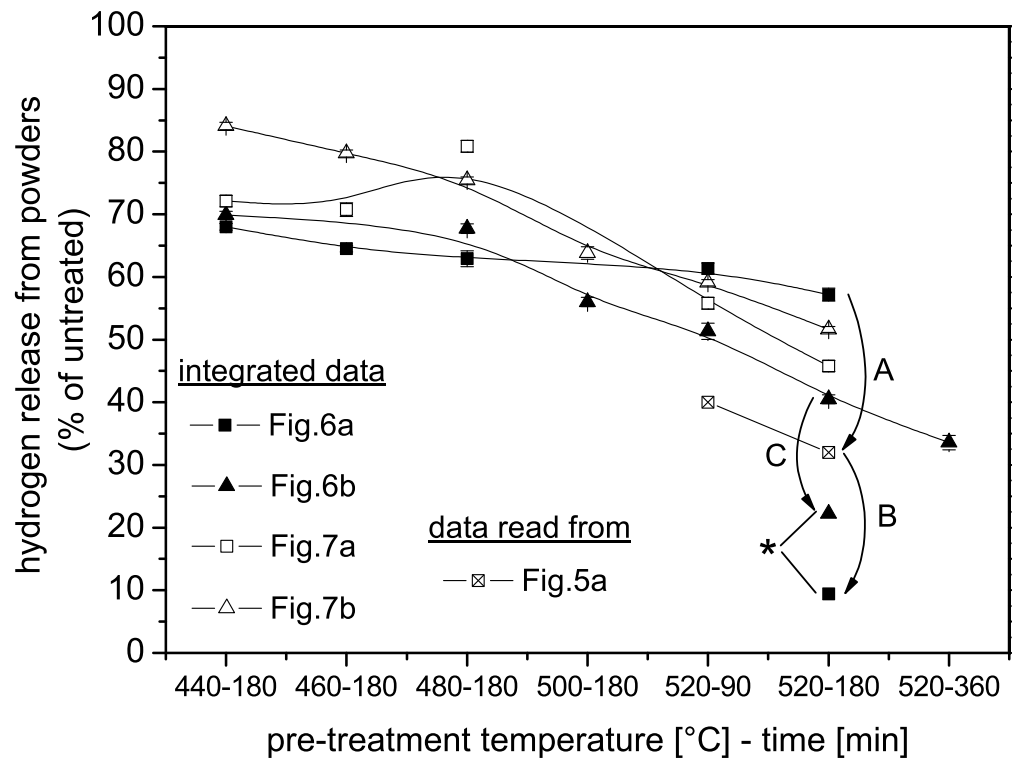

Fig. 15. Total amount of hydrogen released from pre-treated $\mathrm{TiH}_{2}$ powders during isochronal or isothermal heating as a function of pre-treatment parameters. Loose powders and precursors are considered. All values were either obtained by integration of the curves shown in the figures specified or by reading the value directly from Fig. 5a. The asterisk indicates powders pretreated in the TG furnace under a stream of Ar or air. A mass current offset of $3 \times 10^{-13}$ A was taken into account for Fig. 7b. Values for pre-treated powders are normalised to untreated powder and expressed in \%. Error bars were derived from various measurements corresponding to the same parameter set. Arrows compare hydrogen contents caused by different heat treatments as discussed in the text. 